IA WAL NoL LIVEAMCFE WATIONAL LAEOAATOFY

Assessing the Long-Term System Value Of Intermittent Electric Generation Technologies

A. D. Lamont

December 21, 2006

Submitted for publication to Energy Economics 
This document was prepared as an account of work sponsored by an agency of the United States Government. Neither the United States Government nor the University of California nor any of their employees, makes any warranty, express or implied, or assumes any legal liability or responsibility for the accuracy, completeness, or usefulness of any information, apparatus, product, or process disclosed, or represents that its use would not infringe privately owned rights. Reference herein to any specific commercial product, process, or service by trade name, trademark, manufacturer, or otherwise, does not necessarily constitute or imply its endorsement, recommendation, or favoring by the United States Government or the University of California. The views and opinions of authors expressed herein do not necessarily state or reflect those of the United States Government or the University of California, and shall not be used for advertising or product endorsement purposes

This work was performed under the auspices of the U.S. Department of Energy by University of California, Lawrence Livermore National Laboratory under Contract W7405-Eng-48. 


\title{
Assessing the Long-Term System Value Of Intermittent Electric Generation Technologies
}

Alan D. Lamont

\begin{abstract}
This research investigates the economic penetration and system-wide effects of large-scale intermittent technologies in an electric generation system. The research extends the standard screening curve analysis to optimize the penetration and system structure with intermittent technologies. The analysis is based on hour-by-hour electric demands and intermittent generation. A theoretical framework is developed to find an expression for the marginal value of an intermittent technology as a function of the average system marginal cost, the capacity factor of the generator, and the covariance between the generator's hourly production and the hourly system marginal cost. A series of model runs are made examining the penetration of wind and photovoltaic in a simple electric generation system. These illustrate the conclusions in the theoretical analysis and illustrate the effects that large-scale intermittent penetration has on the structure of the generation system. In the long-term, adding intermittent generation to a system allows us to restructure the dispatchable generation capacity to a mix with lower capital cost. It is found that large scale intermittent generation tends to reduce the optimal capacity and production of baseload generators and increase the capacity and production of intermediate generators, although the extent to which this occurs depends strongly on the pattern of production from the intermediate generators. It is also shown that the marginal value of intermittent generation declines as it penetrates. The analysis investigates the specific mechanism through which this occurs.
\end{abstract}

Q42: Alternative Energy Resources; intermittent generation technologies; electric generation systems 


\section{Introduction}

It is often assumed that reducing the carbon emissions from electric generation systems will require a significant portion of generation from non-carbon technologies such as wind, photovoltaic (PV), nuclear, and, possibly, coal with carbon sequestration. Naturally, we expect that these low-carbon generation systems will be structured to minimize the total cost of generation. The least-cost design of a system with dispatchable technologies is a well-understood problem. However, designing a system that includes intermittent technologies, such as wind and PV, is not as well understood. This paper first discusses the theoretical economic conditions required for the least-cost design of a system with intermittent generation technologies. Then, using a simple system model, it illustrates the penetration of intermittent technologies as a function of their costs and the structural changes in the rest of the system that occur along with the intermittent penetration.

Much of this discussion focuses on the marginal value of an intermittent technology. From an economic standpoint, a technology should penetrate the system as long as its marginal value is greater than its marginal cost. However, the value of a technology depends on the time horizon over which benefits are counted. The value of an intermittent technology will be realized over several time horizons depending on the possibilities for adjusting the capacities and operation of the balance of the system. In the very short term, the capacities of the rest of the generators cannot be adjusted and the only benefit from the intermittent generators is a savings in fuel and operating costs of the other generators. Over a somewhat longer time horizon we can consider the reliability benefits of an intermittent generator. Adding an increment of intermittent generator will tend to improve the reliability of the system as a whole by increasing the reserve margin at some hours of the year. The capacity of the dispatchable generators can then be reduced while still maintaining the same level of reliability. Kirby et al (2003) measures the reliability benefit in terms of a fraction of a peaker plant that could be replaced by a wind generator. They found the capacity credit to be in the order of $57 \%$ for PV and from 22 to $26 \%$ for wind at various sites in California. This benefit would be realized by reducing the amount of peaker capacity on the system. Thus the economic benefit of one unit of intermittent capacity would be on the order of 20 or $60 \%$ of the cost of one unit of peaker capacity. We note that this benefit would not be realized immediately. It would probably be realized over time by reducing the amount of capacity added to the system in the future.

Over a longer time horizon, adding an increment of intermittent generation changes the optimal mix of the dispatchable technology capacities. As we will see below, this new mixture will have a lower overall cost. It will tend to have a lower total capital cost, but not necessarily a lower operating and fuel cost. Several authors have noted this effect. Chowdhury (1991) notes that adding intermittents results in a saving in the optimal expansion plans for a utility. Grubb $(1988,1991)$ examines the long-term effects on the optimal mixture of dispatchable technologies and concludes that this is the primary benefit of introducing intermittents. 
Although there is a long-term benefit from introducing intermittents, the marginal benefit from each increment of intermittent capacity decreases as more capacity is added. This has been observed by several authors (Short et al, 2003; Bouzguenda and Rahman, 1993; Hirst, 2004;), though they have not necessarily assessed the reason. Grubb (1988, 1991) and Kelly and Weinberg (1993) also note the decline in marginal value and observe that it arises from the fact that an intermittent technology begins to displace lower cost generators and thus contributes less and less to the system as it penetrates. The present paper extends and quantifies that observation. Understanding why and how much the marginal cost declines is essential to designing systems with intermittent technologies so that they will have the largest benefit to the system as a whole.

This paper develops theoretical equations for the long-term marginal value of an intermittent generator in an energy system as a function of its capacity factor and the coincidence between its generation and the system marginal cost. This is followed by an analysis of a simple system to illustrate the use of the equation and some general conclusions about the impact of intermittent generators on the structure of the system.

Along with the capital and operating costs of an intermittent technology, there are additional costs of integrating the technology into the system (Kelley and Weinberg, 1993). These integration costs stem from the fact that the generation from the intermittents can vary quickly and unpredictably, particularly in the case of wind. This requires that additional generators be kept on spinning reserve and that other generators on the system may be ramped up or down quickly as the intermittent output varies.

Although this is indeed a cost of intermittent generation, several studies have found that it is not necessarily highly burdensome (Kirby et al, 2003; deCarolis and Keith, 2005; Hirst, 2004). In this paper we do not take these costs into account on the grounds that they are second order effects compared to the structural effects that we are investigating. One can also take the optimistic view that new strategies will be developed to cope with these variations, perhaps using better prediction and developing technologies that can respond quickly at low cost.

\section{Analytic approaches to assessing the economics of intermittent technologies}

The standard "screening curve" methodology is a basic way of determining the optimal capacities of base load, intermediate, and peaking capacity (Stoft, 2002; Shaalan, 2003; Kelly and Weinberg, 1993). This method is based on a well-defined optimization that minimizes the total cost of generation, while meeting the loads in each hour. This type of analysis is structured using a load duration curve, which represents the cumulative probability distribution over system loads during the year. For analyzing systems that use only dispatchable technologies this representation is sufficient, since, to a first approximation, it does not matter at which hour each load level occurs. The dispatchable generators can be dispatched to serve the load.

However, intermittent generators cannot be dispatched - they generate on their own schedule without regard to when they are needed. Consequently, the chronological coincidence between generation and load is essential for analyzing the economic value of intermittent technologies. Intermittent technologies can be included in a screening curve 
analysis by treating them as a "negative load": subtracting the generation of a given intermittent capacity from the load in each hour to obtain a residual load for each hour. The load duration curve for the residual loads is constructed and the screening curve analysis is applied to determine the optimal capacity of the dispatchable generators to meet the residual load (Kelly and Weinberg 1993). This approach does not directly analyze the optimal capacities of the intermittent generators and does not provide direct information about the marginal values of intermittent technologies.

Another approach for analyzing intermittents builds a load duration curve by evaluating the system load in a set of typical periods during the year-winter nights, winter mornings, winter daytime, etc. (EIA, 2001; Short et al, 2003). The set of typical periods covers all of the hours of the year. Based on this, a load duration curve can be constructed. Then the average output of the intermittent generator during each of these typical periods is determined. The intermittent is represented as a generator with an output that is constant during each typical period, but varies from period to period. This approach does approximate the chronological coincidence of load and generation and it models the capacity factor of the intermittent correctly. But, it averages out the production of the intermittent generator and eliminates the fact that the intermittent generator's output can be highly variable from day to day. There is a substantial difference between a generator that produces at $20 \%$ of capacity all of the time and one that generates at $100 \%$ of capacity $20 \%$ of the time, even though they both have a $20 \%$ capacity factor.

As noted above, the screening curve method is based on a well-defined optimization problem. The screening curve analysis finds the optimal capacity of each type of generator to minimize the total annual cost of meeting a particular pattern of loads (See Shaalan, 2003, or Stoft, 2002, for detailed discussion.) The screening curve approach is an idealization of an electric generation system which captures the dominant components of cost for the technologies and provides a basic analysis of the way that capital and operating costs of different types of generators interact with the patterns of loads and generation to structure an efficient electric generation system. In the real world, system planning takes these issues into account as well as a broader range of generation technologies, transmission costs, and operational issues such as the commitment and ramping of generators.

This paper starts by extending the screening curve method to include intermittent technologies. These equations provide insight into the economic forces that encourage or discourage intermittent technologies. From these extended equations we can derive an equation that expresses the value of an intermittent capacity to the system as a whole. This expression divides the value into two components: one that is a function of the economics of the baseload technology and the capacity factor of the intermittent technology, and another which is a function of the match between the hourly generation of the intermittent and the hourly energy values on the system.

\section{Mathematical formulation}

This section structures the formal optimization problem and derives equations for the optimality conditions that take into account the intermittent generators on the system. 
To state the problem: Let us assume that there is a set of generators meeting the demands over a year's operation. For convenience we will break the year into one hour periods ( 8,760 hours for the year), although the analysis could be conducted at any other period length. At each hour there is a demand to be met by dispatching the generators to meet the demand at minimum cost. The generators can be a mixture of dispatchable and intermittent generators. Given the set of hourly demands, costs and efficiencies of the generators, and the hourly production of the intermittent generators, what is the cost minimizing configuration and operation of all the generators in the system.

\section{Nomenclature}

There is a set of generation technologies each denoted by the subscript $g$. These are dispatched to meet the demand in each hour, Dmnd $_{h}$. Some of these technologies are intermittent so that in some hours their available capacity is only a fraction, $P F_{g, h}$, of their nameplate (or peak) capacity. For a dispatchable generator, $P F_{g, h}$ is 1.0 for each hour (we ignore forced outages in this analysis). Each generator will be dispatched to its full available capacity for at least one hour in a year ${ }^{1}$. For the formulation below, it is essential to keep track of the hours in which a technology is fully dispatched. We denote the set of hours that generator $g$ is dispatched to its available capacity as $H_{g}^{*}$. The full set of variables and parameters is as follows:

Objective function:

CSTtot $=$ total annual cost of system, $\$ / \mathrm{yr}$

Decision variables:

$C A P_{g}=$ the capacity of generator $g$, which is the peak output available from generator $g, \mathrm{~kW}$.

Out $_{g, h}=$ output of the generator $g$ in the hour h, $\mathrm{kW}$.

Derived variables:

$H_{g}^{*} \quad=\quad$ the set of hours where generator $g$ is dispatched to its full available capacity.

$\mathrm{CF}_{\mathrm{g}}=$ capacity factor of generator $g$.

MargVal $_{g}=$ the marginal value of a unit of capacity for generator $g$.

Model parameters:

1 If it is not dispatched to full capacity at least once, then it has more capacity than is optimal. 


$$
\begin{aligned}
& \text { CSTcap }_{\mathrm{g}}=\text { annual capital cost of one unit of capacity for generator } g, \$ / \mathrm{kW} \text { - } \\
& \text { yr. } \\
& \text { CSTvar }_{g}=\text { variable operating cost of generator } g, \$ / \mathrm{kWh} \text {. } \\
& \text { Dmnd }_{h}=\text { demand in hour } h, \mathrm{~kW} \text {. } \\
& P F_{g . h}=\text { production factor for generator } g \text { in period } h \text {. This is the fraction }
\end{aligned}
$$

\section{Analysis}

We will minimize the total annual cost of the system, which is the sum of the annualized capital costs for all the generators plus their operating costs over the year. However, the minimization is subject to the constraint that the total output each hour must equal the demand that hour, and each generator must be dispatched at its available capacity, or less.

Minimize:

$$
\text { CSTtot }=\sum_{g} \text { CAP }_{g} \bullet \text { CSTcap }_{g}+\sum_{h} \sum_{g} \operatorname{CSTvar}_{g} \bullet \mathrm{Out}_{g, h}
$$

Subject to:

$$
\begin{aligned}
& \text { Out }_{g, h} \leq P F_{g, h} \bullet C A P_{g} \text { for all } g \text { and } h \\
& \sum_{g} \text { Out }_{g, h}=\text { Dmnd }_{h} \text { for all } g, h
\end{aligned}
$$

For the purposes of the theoretical analysis below, it is useful to convert the inequality in equation 2 into an equivalent equality. The inequality can be removed by defining the set of hours that a generator is dispatched to its full available capacity. A generator's output will be equal to its available capacity in those hours that the total load exceeds the capacity of that generator, plus the available capacity of all those generators that precede it in the loading order. Denote this set of hours as $H_{g}^{*}$ for generator $g$. For a dispatchable generator this set of hours is not generally known a priori since it depends on the capacities of all the other generators, which in turn depend on the capital and operating costs of the other generators. Rather, the set of hours $H_{g}^{*}$ for the dispatchable generators is found in the solution to the optimization problem. Intermittent generators, however, have essentially zero operating cost, so they are first in the dispatch order. Therefore they are always dispatched to their full available capacity. By explicitly defining this set of hours for each generator, we can develop some useful relationships in the discussion that follows. With this definition, equation 2 can be written as 


$$
\text { Out }_{g, h}=P F_{g, h} \bullet C A P_{g} \quad \text { for } h \in H_{g}^{*} \text {, for each } g \quad \text { 2a }
$$

Based on these we form the Lagrangian as:

$$
\begin{aligned}
L= & \sum_{g} C A P_{g} \bullet \text { CSTcap }_{g}+\sum_{h} \sum_{g} \text { CSTVar }_{g} \bullet \text { Out }_{g, h}+ \\
& \sum_{h} \lambda_{h}\left(\text { Dmnd }_{h}-\sum_{g} \text { Out }_{g, h}\right)+ \\
& \sum_{g} \sum_{h \in H_{g}^{*}} \gamma_{g, h}\left(\text { Out }_{g, h}-P F_{g, h} \bullet C A P_{g}\right)
\end{aligned}
$$

To determine the conditions to be met at the optimum, we differentiate with respect to the output of each generator for each hour, and with respect to the capacity of each generator.

$$
\begin{aligned}
& \frac{\partial L}{\partial \text { Out }_{g, h}}=0= \begin{cases}\text { CSTvar }_{g}-\lambda_{h} & \text { if } h \notin H_{g}^{*} \\
\text { CSTvar }_{g}-\lambda_{h}+\gamma_{g, h} & \text { otherwise }\end{cases} \\
& \frac{\partial L}{\partial C A P_{g}}=0=\text { CSTcap }_{g}-\sum_{H_{g}^{*}}\left(\gamma_{g, h} \bullet P F_{g, h}\right) \quad \text { for each } g
\end{aligned}
$$

We note that $\gamma_{g, h}=\lambda_{h}-C \operatorname{var}_{g} \quad$ when technology $g$ is dispatched to its available output (i.e. $\mathrm{h}$ is in $H_{g}^{*}$ ). We can then rewrite equation 6 as:

$$
\text { CSTcap }_{g}=\sum_{h \in H_{g}^{*}}\left[\left(\lambda_{h}-\text { CSTvar }_{g}\right) \bullet P F_{g, h}\right] \quad \text { for each } g
$$

The first condition in equation 5 applies when generator $g$ is not dispatched to its full available output in hour $h$, the generator should be dispatched such that its marginal operating cost is $\lambda_{h}$, the marginal system cost in that hour, which is the variable cost of the most expensive generator on the system in that hour. The variable costs in this formulation are constants so a generator is dispatched if its variable cost is less than or equal to $\lambda_{h}$, and is not dispatched otherwise. The fact that the variable costs are constant is not crucial in this formulation. If variable costs changed as a function of output, the generator would be dispatched up to the level that its variable cost equals the system marginal cost. If the second condition applies, the generator is dispatched to its capacity. In that case its marginal operating cost is less than or equal to $\lambda_{h}$.

The value $\gamma_{g, h}$ is the shadow value on the constraint that generation cannot exceed capacity. $\gamma_{g, h}$ can be interpreted as the amount the system cost would be reduced if there were an incremental unit of energy available from the generator at that hour. This is the same as the difference between the generator's marginal cost that hour and the system marginal cost. If all generators receive a price equal to the system marginal cost, then $\gamma_{g, h}$ is the additional net revenue the generator receives that hour over and above its operating cost per unit of energy produced. 
Turning now to equation 6, we note that $P F_{g, h}$ is the amount of additional output that a unit of capacity can produce that hour. That is, if $P F=1.0$, an additional unit of capacity can generate an additional unit of energy. If $P F=0.5$, a unit of capacity can only generate 0.5 units of energy in that hour. Since $\gamma_{g, h}$ is the difference between the system price and the generators marginal cost at that hour, $\gamma_{g, h} \bullet P F_{g, h}$ is the additional net revenue that the generator would receive in that hour from an addition unit of capacity. Taken as a whole, equation 6 implies that the system should be configured so that the sum of the additional net revenues to a generator received from an additional increment of capacity will just be equal to the cost of an increment of capacity. Viewed from the system perspective, this condition implies that the cost of an additional unit of capacity should be just equal to the total benefit that it provides to the system.

If we multiply equation 6 by the total capacity installed for generator $g$, the sum of the payments over all the hours, $\sum_{h} \gamma_{g, h} \bullet P F_{g, h} \bullet C A P_{g}$, is equal to the total annual capital cost of the installed capacity.

\section{Marginal value of an intermittent generator}

One of the keys to addressing the penetration of intermittent technologies is evaluating the marginal value of capacity for an intermittent technology. The marginal value of a generator is expressed by the RHS of equation 7. When equation 7 is applied to an intermittent generator we note that the variable cost of an intermittent generator (at least those considered here) is essentially 0 . Since the marginal cost is 0 , the intermittent generator is first in the loading order and is always dispatched to its full available capacity in each hour. Therefore, $H_{g}^{*}$, includes all of the hours of the year for an intermittent generator. Given these facts, the expression for the marginal value of an intermittent generator simplifies to:

$$
\operatorname{MargVal}_{g}=\sum_{h=1}^{H}\left[\lambda_{h} \bullet P F_{g, h}\right]=H \bullet E\left(\lambda \bullet P F_{g}\right)
$$

Where $E(\bullet)$ is an expected, or average, value. The values of $P F$ and $\lambda$ can be considered to be random variables in each hour. From that point of view the RHS of equation 8 is actually a component of the covariance between $P F$ and $\lambda$. The definition of the covariance is:

$$
\operatorname{Cov}\left(\lambda, P F_{g}\right)=E\left(\lambda \bullet P F_{g}\right)-E(\lambda) \bullet E\left(P F_{g}\right)
$$

Note that $E\left(P F_{g}\right)$ is just the capacity factor of the intermittent generator over the year, $C F_{g}$. Substituting the expression for $E\left(\lambda \bullet P F_{g}\right)$ into equation 8 results in

$$
\operatorname{MargVal}_{g}=H \bullet E(\lambda) \bullet C F_{g}+H \bullet \operatorname{Cov}\left(\lambda, P F_{g}\right)
$$

Equation 10 is the primary theoretical result from this study. It shows that the marginal long-term value of an intermittent generator can be divided into two components. The first component is strictly a function of the capacity factor of the intermittent generator and the marginal costs on the system as a whole. This component 
reflects the total energy that a generator can provide over the year. If that energy were delivered at uniformly random hours, this component would reflect the expected value of that energy. For clarity, note that $E(\lambda)$ is the time weighted average price, not the energy weighted average price that is often used to assess the value of generators.

The second component is a function of the intermittent pattern of generation and the pattern of marginal costs on the system. This term is positive if the generator tends to generate when the system marginal cost is high, and it is negative if the generator tends to generate when the system marginal cost is low. Frequently we refer to the "load matching" capability of an intermittent generator. Equation 10 shows that the value of a generator is determined by its ability to match the system marginal cost. Although load and system marginal cost are generally correlated, we will see later that this correlation attenuates as intermittent generation penetrates the system.

In the examples below we will evaluate the penetration of wind and PV for a wide range of capital costs. Equation 10 is useful partly due to the fact that the sum of the system marginal costs (and therefore the average cost) does not change under a very wide range of intermittent penetration. The next section provides a proof of this proposition. This means that the first term in equation 10 is constant, for our purposes, as the intermittent technology penetrates the system. Only the second term, the system matching term, changes under different scenarios of costs of intermittent technologies, or level of intermittent penetration. Within the system matching term, only the pattern of system marginal costs changes. Understanding the penetration of intermittent technologies, and its effect on carbon emissions, is basically a matter of understanding how the pattern of system marginal costs changes under changing conditions.

\section{Sum of marginal system costs is determined by costs of the baseload generator}

The sum of the marginal system costs over a year is a factor in the analysis of the marginal value of intermittent generators developed below. It happens that over a broad range of conditions, the sum of the system marginal costs is in fact, a constant. This can be seen from equation 7. If we consider a base load generator, the factor $P F_{g, h}$ would nominally be 1 for all hours of the year since the baseload nominally operates at full capacity in all hours. This is not quite true and we will be more accurate in a moment. Rearranging equation 7 we can derive the following for the baseload generator:

$$
\operatorname{CSTcap}_{B}+\sum_{h \in H_{B}^{*}} \operatorname{CSTvar}_{B}=\sum_{h \in H_{B}^{*}} \lambda_{h}
$$

Following along with the presumption that the baseload is fully dispatched every hour implies that $\mathrm{H}_{\mathrm{B}} *$ includes all the 8,760 hours in the year, equation 11 can be simplified to

$$
\operatorname{CSTcap}_{B}+H \bullet C S T \operatorname{Var}_{B}=\sum_{h=1}^{H} \lambda_{h}
$$

That is, the sum of the marginal costs is equal to the marginal capital cost of baseload capacity plus the marginal cost of operating the marginal increment of baseload capacity over a year. This result is in fact more general than is implied by the equations above. It can be extended and generalized by the following definition and proposition; 
Definition of baseload generator: A generator is a baseload generator in an optimized system if it is dispatched to some non-zero level in every hour of the year, and it is dispatched to its full capacity in at least one hour of the year.

We note that the system would not be cost optimized if the generator were not dispatched to full capacity at least once over the year.

Proposition: If there is a baseload generator in the system, the sum of the system marginal costs is equal to the marginal annual capital cost of the baseload generator plus the marginal cost of operating the baseload generator over all hours of the year.

Proof: From equation 7 it is evident that the sum of the marginal costs over the hours that the baseload is fully dispatched is equal to the marginal cost of the baseload plus the sum of the marginal operating costs over those hours, or

$$
\operatorname{CSTcap}_{B}+\sum_{h \in H_{B}^{*}} \operatorname{CSTvar}_{B}=\sum_{h \in H_{B}^{*}} \lambda_{h}
$$

In the remaining hours of the year, the baseload generator is not full dispatched, but it is dispatched in every hour. Assuming that the system uses merit order dispatching, the baseload generator must have the highest operating cost of all generators dispatched and its marginal generation cost must be the system marginal cost. Consequently, in those hours that are not in the set $H_{B}^{*}$ the marginal cost is CSTvar ${ }_{B}$. We can add the sum of these marginal costs to both sides of equation 13 to obtain:

$$
\operatorname{CSTcap}_{B}+\sum_{h \in H_{B}^{*}} \operatorname{CSTvar}_{B}+\sum_{h \notin H_{B}^{*}} \operatorname{CSTvar}_{B}=\sum_{h \in H_{B}^{*}} \lambda_{h}+\sum_{h \notin H_{B}^{*}} \lambda_{h}
$$

Which reduces to:

$$
\operatorname{CSTcap}_{B}+\sum_{h=1}^{H} \operatorname{CSTvar}_{B}=\sum_{h=1}^{H} \lambda_{h}
$$

This result implies that the sum of the system marginal costs over the year is determined by the capital and operating costs of the baseload technology. The sum of the system marginal costs will be constant as intermittent technologies penetrate. This will be true up to the point that the intermittent capacity is large enough to entirely displace the base load generator in some hours.

\section{Description of the illustrative model}

To illustrate these results the simple model shown in Figure 1 was developed. The model includes baseload, intermediate and peaking generators along with wind and photovoltaic (PV). The model has been developed using demand, PV, and wind data 
from California in 2001. Although the model uses California data, it is not a model of the California energy system. The California data have been used to ensure that the demands and intermittent generation are realistically coordinated in each hour. The parameters and data for the model are described in Appendix A.

Figure 1: Structure of model

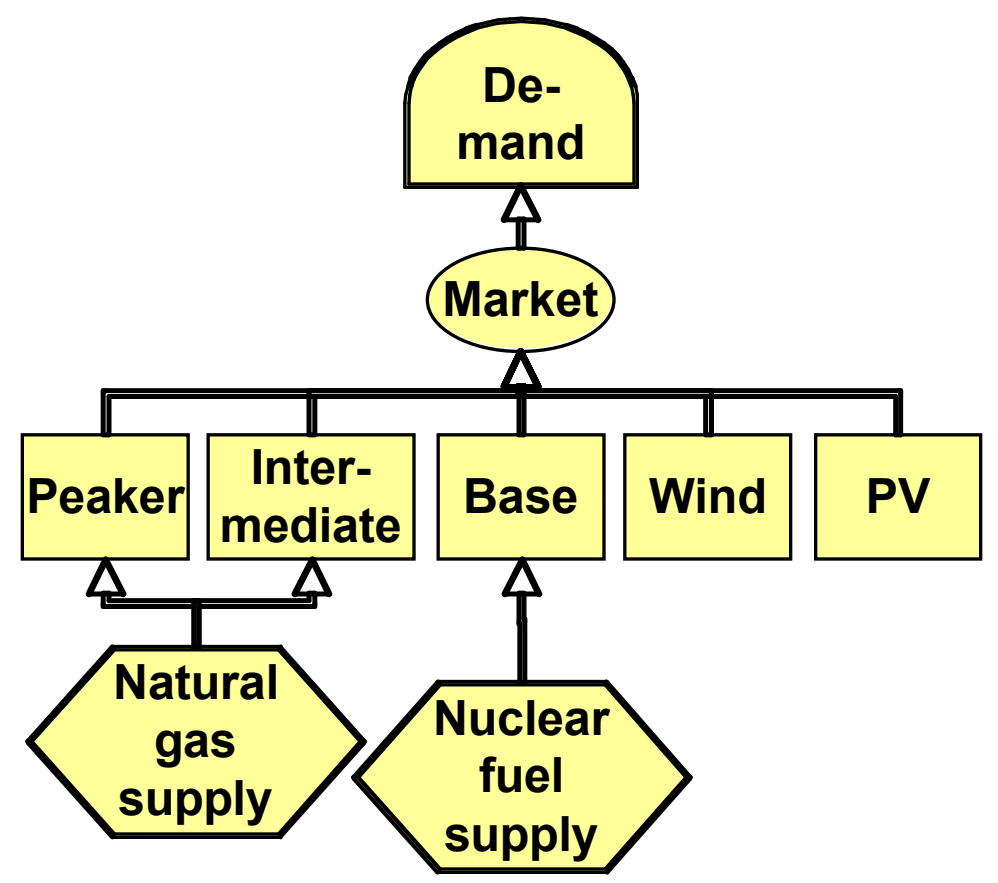

Although the actual California peak load is close to $60 \mathrm{GW}$, the results of this study have been normalized so that capacities are presented in terms of $\mathrm{kW}$ of generation capacity per $\mathrm{kW}$ peak load. Therefore, the capacities shown in the results can be interpreted as fractions of the peak demand. The cost results from the model are shown in costs per $\mathrm{kW}$ of load, or cost per $\mathrm{kWh}$ of generation.

The data set used for the model are convenient for illustrating the impacts of different types of intermittents. The PV generator, naturally, generates during the day close to the peak demand hours. The particular wind pattern used here often blows at night. This analysis contrasts the effects of on-peak and off-peak generation. Note that this wind pattern is only typical of a particular location. Thus comments made here about the behavior of "wind" should only be taken as referring to this wind pattern, not necessarily wind generators in general. One should also note that in these analyses varying amounts of intermittent generation capacity are added to the system. Here it is assumed that the capacity is all added from the same location and consequently all increments of capacity have the same generation pattern. This may be roughly correct for PV since insolation across wide areas tends to follow a fixed pattern. In the case of wind, there are physical limits to the amount of capacity that can be added in any given wind field, and wind fields have somewhat different generation patterns. Consequently, one could not add an unlimited amount of wind capacity with a constant generation pattern as 
is assumed here. This analysis illustrates the general impact of adding intermittents to a system and is not intended to prescribe a system design for California.

\section{Solution method}

The standard screening curve analysis has a convenient graphical solution method. Since there is no such convenient method for solving the problem when intermittents are included, an optimizing solver must be used to solve the equations. We have used the META $\bullet$ Net economic modeling system (discussed in Appendix B) to solve for the optimal system structure, system operation, and the other results that are useful for interpreting the penetration equations.

The solution to the model must also provide that the total revenue received by the generator with the highest operating cost, the "peaker", be sufficient to cover its total installed capital costs and operating costs. In real electric systems there are several possible solutions to this (see, for example Stoft, 2002). Under the solution used here, the value of the marginal system cost, $\lambda_{h}$, is set during those hours in which the peaker is dispatched near capacity so that its total revenue equals its total costs.

\section{Base case analysis without intermittents}

A base case analysis was run to with no intermittent technologies in the system. This was used to compute the sum of the system marginal costs for comparison to the sum predicted by equation 12 . We then used the results of this run to predict the cost at which the wind and PV generators would begin to penetrate the system using equation 10 .

First we use the cost parameters of the base load generator to predict the sum of the system marginal costs. At a 10\% interest rate the marginal annual capital cost of the nuclear baseload is $\$ 281 / \mathrm{kW}$-yr on a continuous compounding basis. Its variable O\&M is $0.00043 \$ / \mathrm{kWh}$, and the fuel cost is $3.1^{*} 0.0046 \$ / \mathrm{kWh}$ (note that 3.1 is the input/output coefficient corresponding to the nuclear generator's heat rate). The total marginal operating cost over a year is $8760 *(0.00043+3.1 * 0.0046)=\$ 129 / \mathrm{kW}$-yr. Therefore, the total marginal cost of building and operating a nuclear baseload generator $=\$ 281+$ $\$ 129=\$ 410 / \mathrm{kW}$-yr. Equation 12 predicts that this should equal the sum of the system marginal costs in the model runs. The model runs give values that vary slightly from this, in the order of $\$ 408$ to $\$ 413 / \mathrm{kW}-\mathrm{yr}$.

Next we assess the marginal long-term values of capacity for the wind and PV, prior to their initial penetration. This should predict the cost at which they will initially penetrate the system. Table 1 calculates the marginal value of wind and PV, prior to their penetration, to be $\$ 123$ and $\$ 101 / \mathrm{kW}$-yr, respectively. Figure 2 and Figure 3 show the penetration of the intermittent technologies as a function of the annual cost of the intermittents. In the model runs, wind first penetrated at about $\$ 123 / \mathrm{kW}$-yr and PV penetrated at about $\$ 102 / \mathrm{kW}$-yr which are consistent with the theoretical predictions. 
Table 1: Predicted marginal annual costs leading to penetration

\begin{tabular}{|l|l|l|}
\hline & \multicolumn{1}{|c|}{ Wind } & \multicolumn{1}{c|}{ PV } \\
\hline Capacity factor & 0.350 & 0.202 \\
\hline Energy term from Eq. 12 (\$/kW-yr) & $410^{*} 0.35=143$ & $410^{*} 0.202=83$ \\
\hline $\begin{array}{l}\text { Covariance production factor and system } \\
\text { marginal cost }\end{array}$ & -0.00225 & 0.00221 \\
\hline $\begin{array}{l}\text { System matching term from Eq. 12 (\$/kW- } \\
\text { yr) }\end{array}$ & $8760^{*}(-0.00225)=-20$ & $8760^{*} 0.00221=18$ \\
\hline Total annual marginal value $(\$ / \mathrm{kW}-\mathrm{yr})$ & 123 & 101 \\
\hline
\end{tabular}

\section{Effects of intermittent generation technologies on system capacities, generation, and costs}

A key question of this research is the effect that intermittent technologies have on the optimal structure and cost of the rest of the system. To examine this, a series of runs were made gradually reducing the capital cost of the intermittent technologies so as to induce their penetration into the system.

Figure 2 and Figure 3 show the penetration and changes in system structure as a function of the marginal annual costs of the wind and PV technologies.

Figure 2: Penetration of wind as a function of wind annual cost

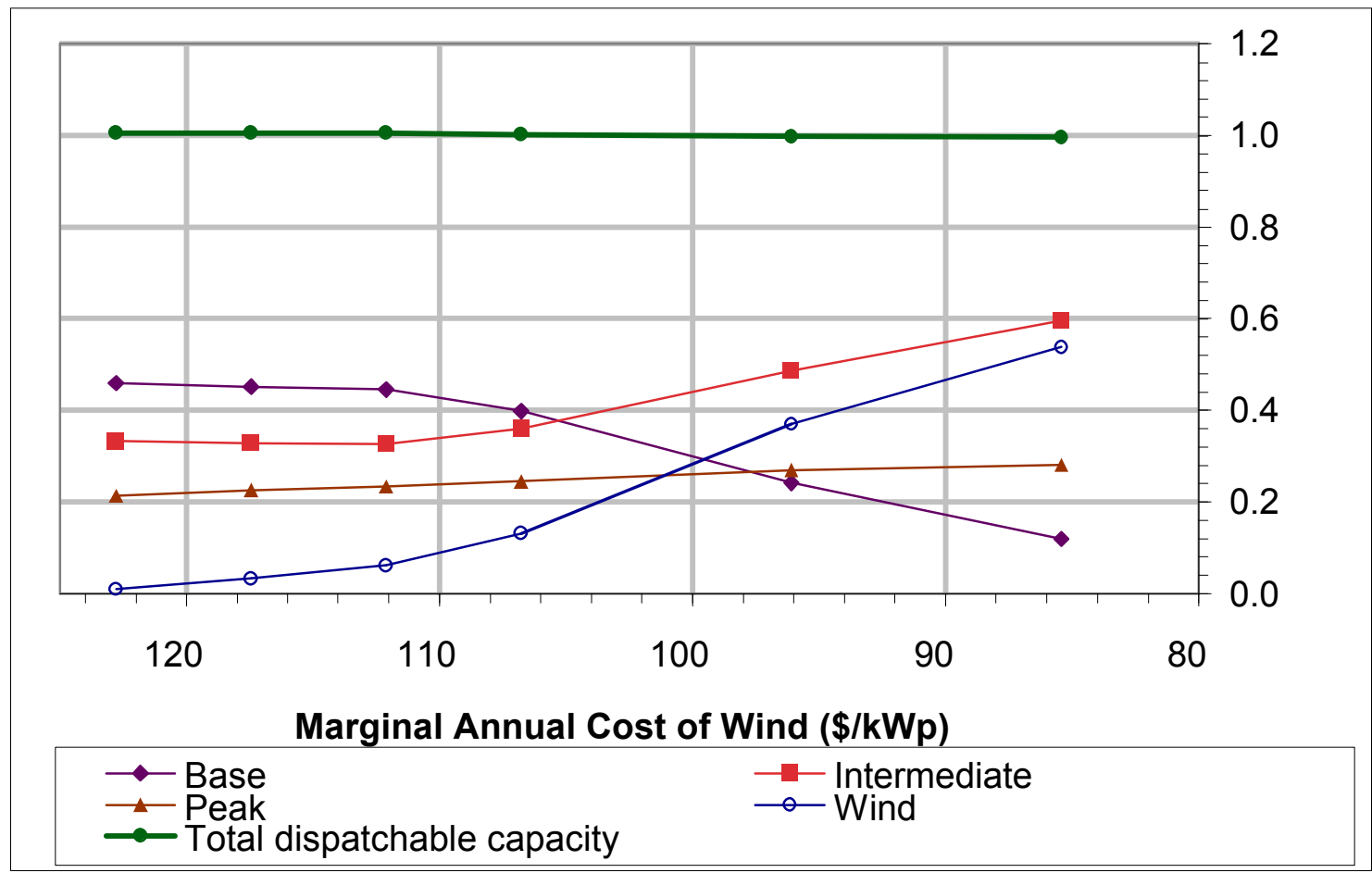

We note that the total capacity of the dispatchable generators does not change as the wind 
penetrates the system since for this wind pattern there is no significant wind generation during the peak hours of the year. The value of the wind generator arises from the restructuring the capacities of the dispatchable generators.

Figure 3: Penetration of $P V$ as a function of $P V$ annual cost

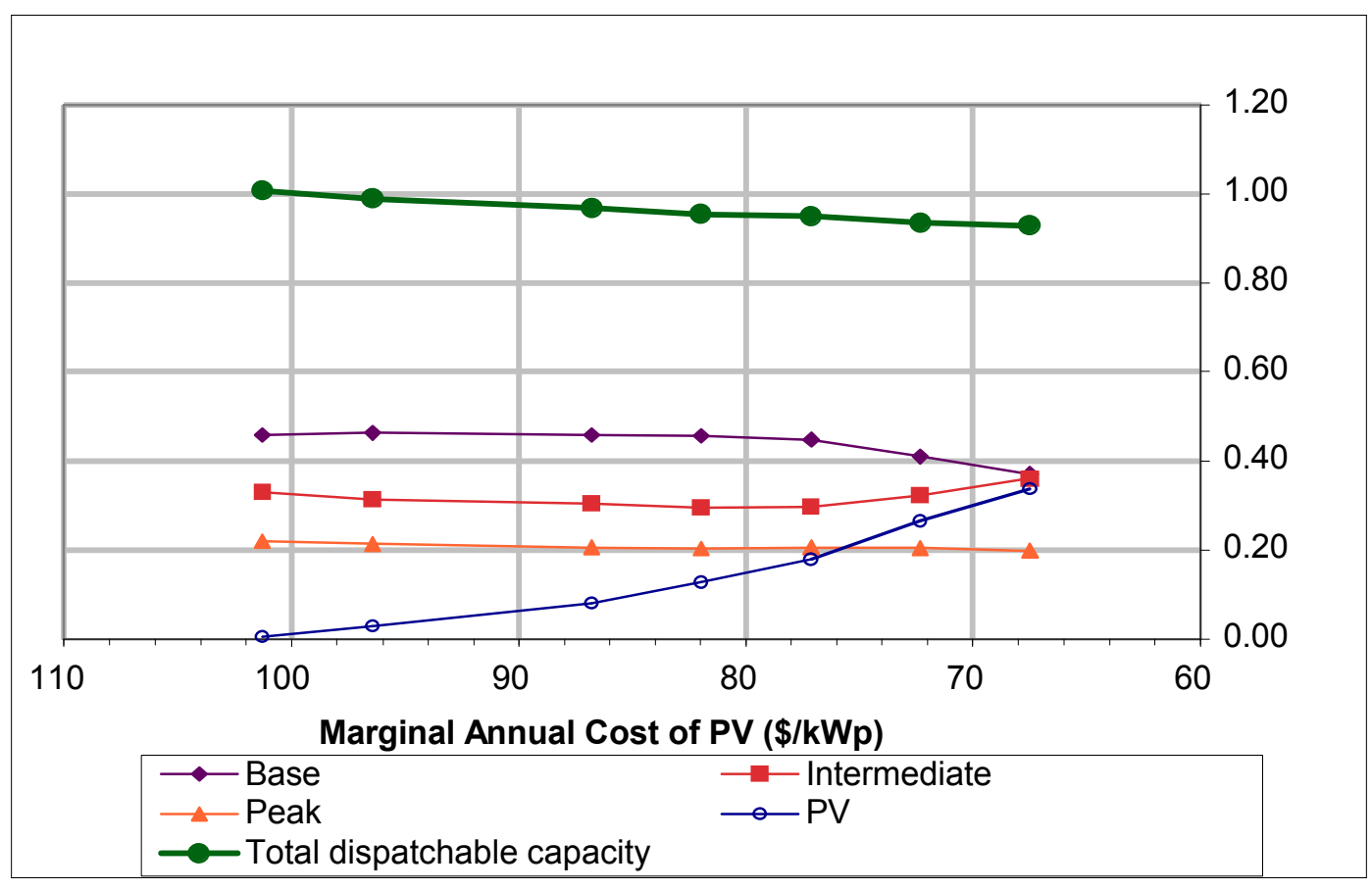

Figure 4 and Figure 5 show the change in system structure and the energy generation as a function of the wind penetration. 
Figure 4: Change in system structure as wind penetrates the system

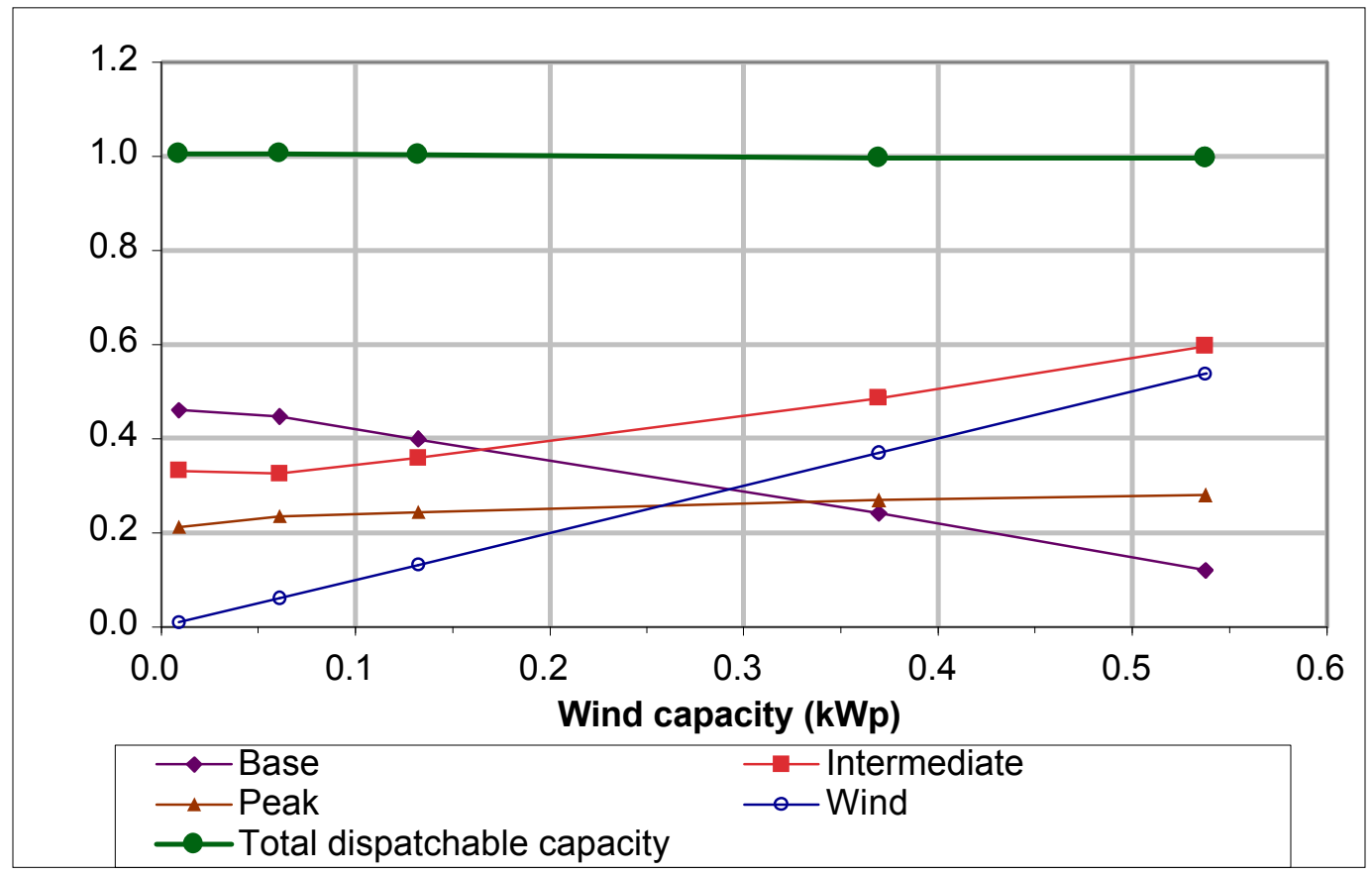

The penetration of the wind capacity drives down the baseload capacity. The initial wind penetration has only a small effect on the other technologies. However, after a penetration of $0.06 \mathrm{kWp}$ (i.e. $6 \%$ of peak load), the baseload capacity declines in nearly direct proportion to the increase in the wind capacity, while the intermediate capacity increases as the wind penetrates. Figure 5 shows that the energy generation follows the same pattern: energy from the wind increases linearly with wind penetration, baseload generation decreases essentially linearly, and intermediate generation increases nearly linearly with wind penetration. 
Figure 5: Energy generation by technologies as a function of wind penetration

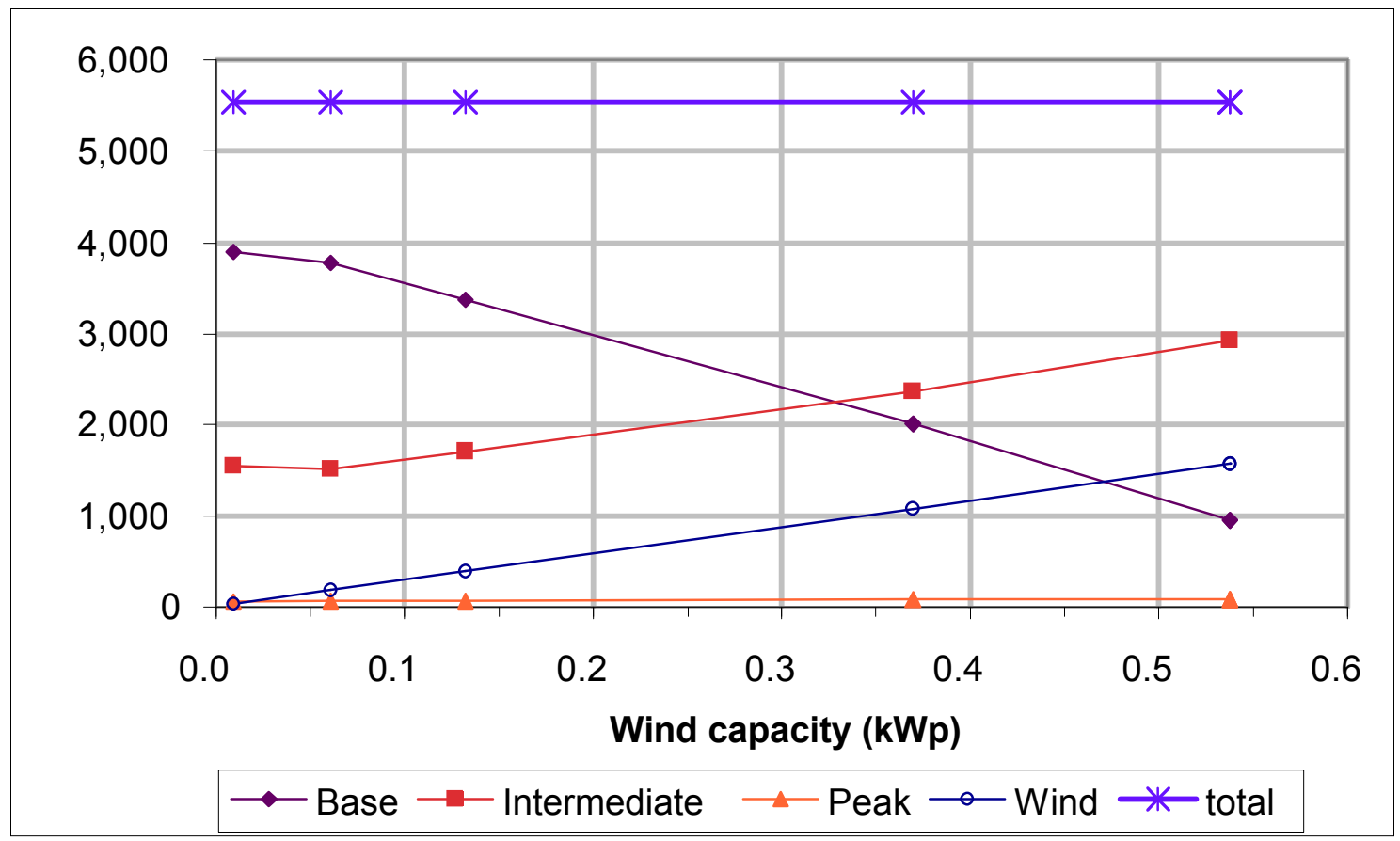

The effects of PV penetration appear to be somewhat different. Figure 3 shows the penetration of PV as a function of its annual cost. Figure 6 shows the change in system structure as PV penetrates. Initially, there is a slight decline in the capacities and the generation of the base load and the intermediate technologies. However, once PV reaches a penetration of about $0.13 \mathrm{kWp}$ (i.e. $13 \%$ of peak load) the baseload capacities and generation decline, while the intermediate capacity and generation increase with PV penetration.

The different effects of the wind penetration and the PV generation on the optimal baseload capacity will be discussed below. 
Figure 6: Change in system structure as PV penetrates the system

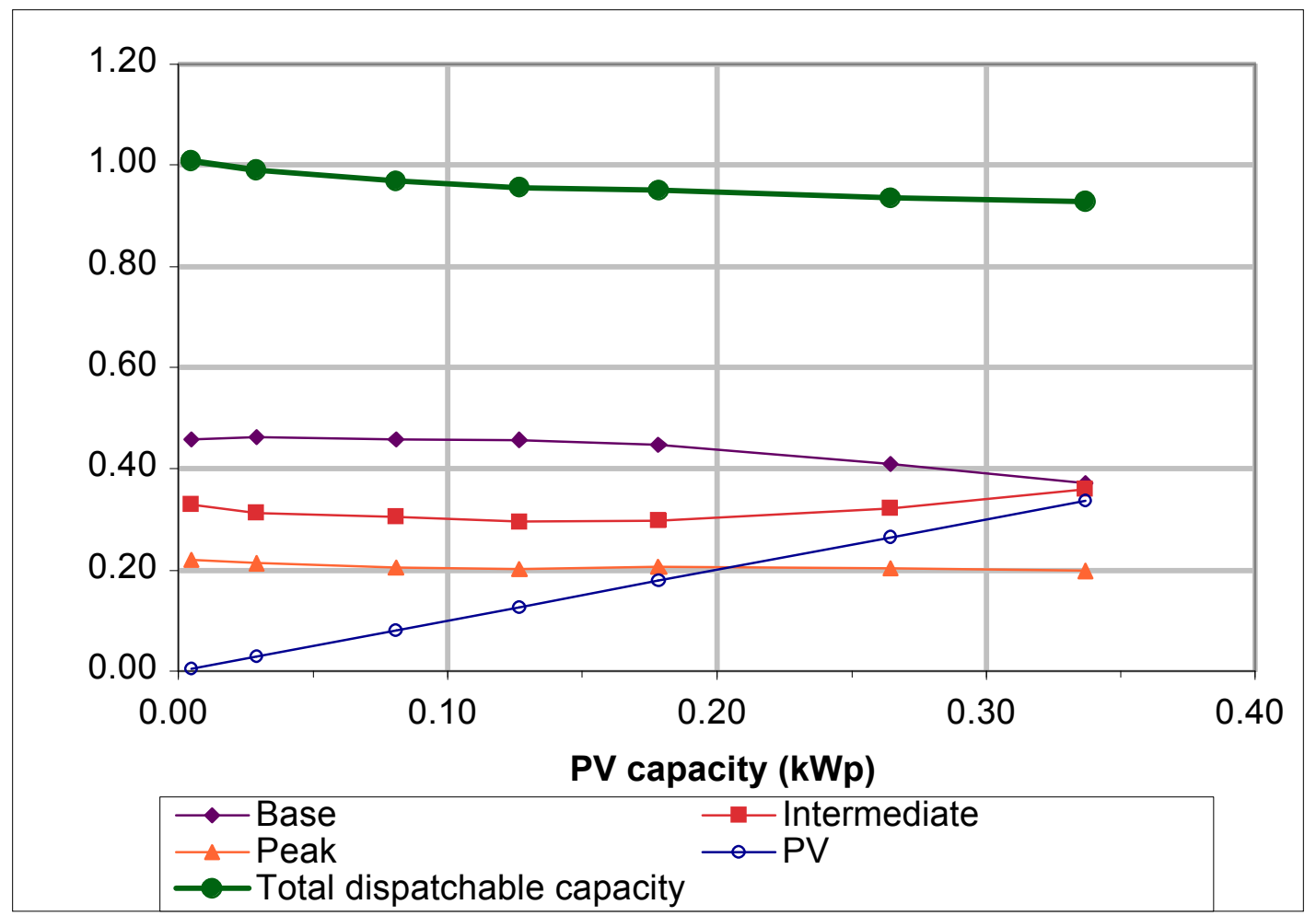

The generation by each technology is shown in Figure 7, as a function of PV penetration. Here again we see that once PV penetrates to the point that it displaces the base load capacity, the baseload generation begins to decrease and the intermediate generation increases. In both the wind and the PV cases, high penetration by the intermittent technology displaces base load generation and increases intermediate generation. 
Figure 7: Energy generation by technologies as a function of $P V$ penetration

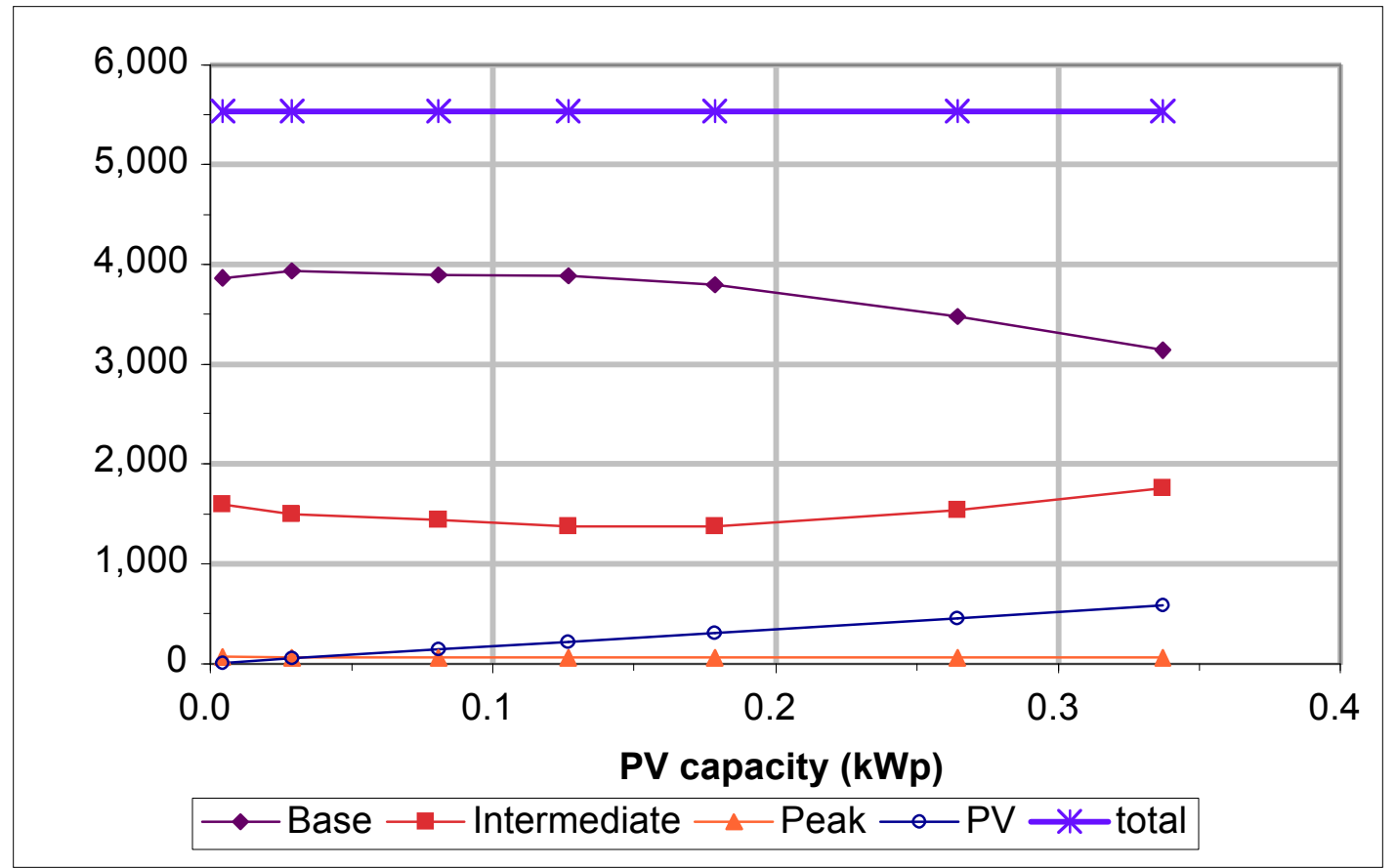

Introducing the intermittent capacity allows the dispatchable part of the system to be reconfigured to reduce the capital and operating cost of the dispatchable system. In both the wind and the PV cases the total dispatchable capacity is still essentially equal to the peak demand. However, the mix of capacities and the generation from each technology is changed to substantially reduce the total dispatchable system cost.

Figure 8 shows the effect the penetration of the wind has on the costs of the dispatchable technologies. The upper envelope of these costs is the total capital and operating cost of the dispatchable technologies. This declines as the wind penetrates the system. At any level of wind penetration, the slope of this line is equal to the marginal reduction in the total dispatchable system costs, per unit of wind capacity added to the system. When the system is optimally structured, this slope is also equal to the marginal capital cost of the wind technology, at that level of penetration. 
Figure 8: Costs components as function of wind penetration

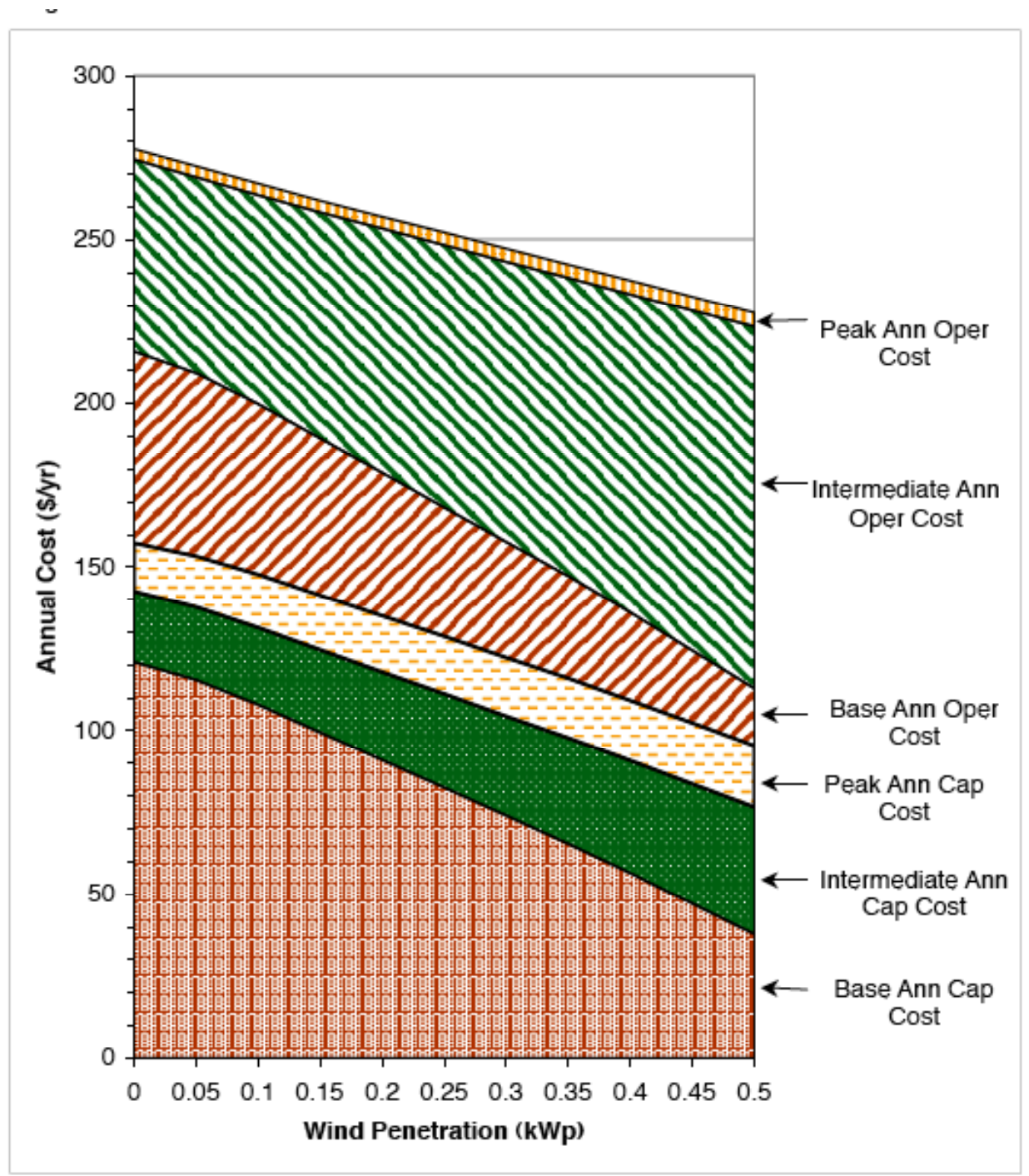

The slope of the total dispatchable cost curve declines (becomes less negative) as the wind penetrates. Initially it is about $\$ 125 / \mathrm{yr}$ per $\mathrm{kWp}$. At the penetration level of $0.45 \mathrm{kWp}$ the slope has declined to about $\$ 100 / \mathrm{yr}$ per $\mathrm{kWp}$. The decline in slope of the dispatchable cost curve corresponds to the decline in the marginal value of wind generation as it penetrates the system.

From Figure 8 we see that the value of the wind comes from the reduction in the capital cost components, not from the operating cost components, consistent with Grubb's (1988) earlier observations. In fact, the operating cost component show a very slight tendency to rise as wind penetrates.

Figure 9 shows the change in cost structure as PV penetrates the system. Initially there is only a light decline in capital costs, but a marked decline in operating costs. Once the PV penetration reaches about $0.15 \mathrm{kWp}$, the capital costs begin to decline and the operating costs increase. 
Figure 9: Cost components as a function of $P V$ penetration

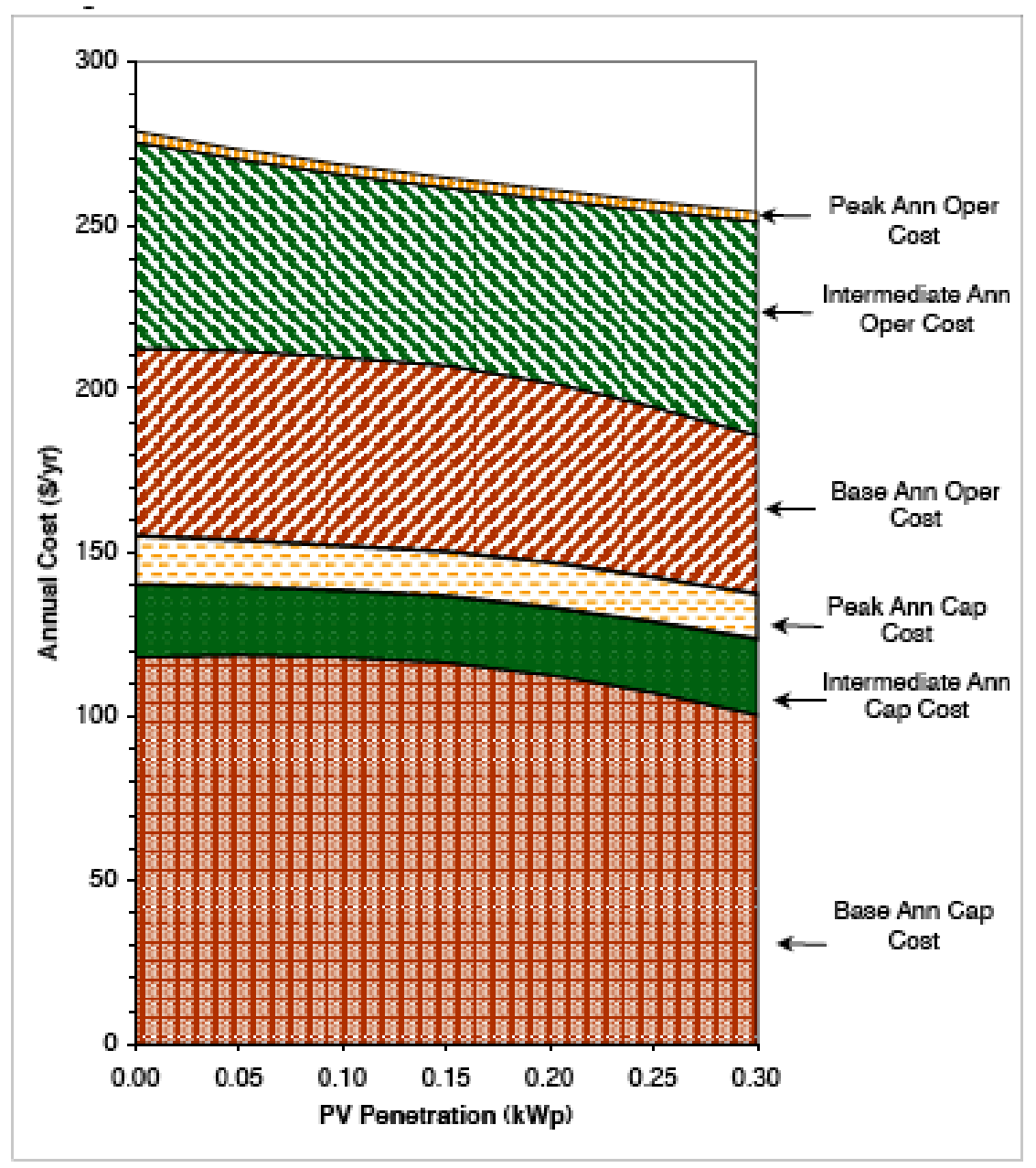

From both of these examples, it is apparent that the penetration of intermittent technologies does not necessarily reduce the operating costs of the long-term system. In fact, the operating costs may increase. The primary benefit from the intermittent technology is a restructuring of the capital cost of the balance of the system.

\section{Decline in the baseload capacity}

The decline in the baseload capacity appears to be a corollary to the penetration of the intermittents. This decline can be viewed from the standpoint of the base load generator. The generation from wind and PV tends to come in bursts rather than as a steady flow. When this occurs, the intermittent displaces the generators with the higher marginal costs. In these examples the intermittent displaces intermediate generation in the early stages of penetration. As long as the intermittent only displaces intermediate generation, it has little effect on the system marginal costs - the intermediate generator remains the marginal generator. Once the intermittent capacity reaches a certain point, it begins to displace baseload generation in at least a few hours, lowering the system marginal cost to the marginal generation cost of the baseload. If this happens for many 
hours during the year, the baseload generator can no longer earn enough revenue to cover both its capital and operating costs. The base load responds by reducing its capacity. This reduces the number of hours per year that it is the marginal generator and brings its revenues up to the level needed to cover both capital and operating costs.

Figure 10 and Figure 11 illustrate the impact of wind generation on the baseload capacity. Figure 10 shows the system structure and system dispatch in a ten day period in March, with no intermittents. The base load capacity is at the optimal level such that it is just below most of the troughs in demand. Only occasionally is the demand below the baseload capacity (there is one instance at around 217 hours in this example)

Figure 10: Dispatch with no intermittents in March

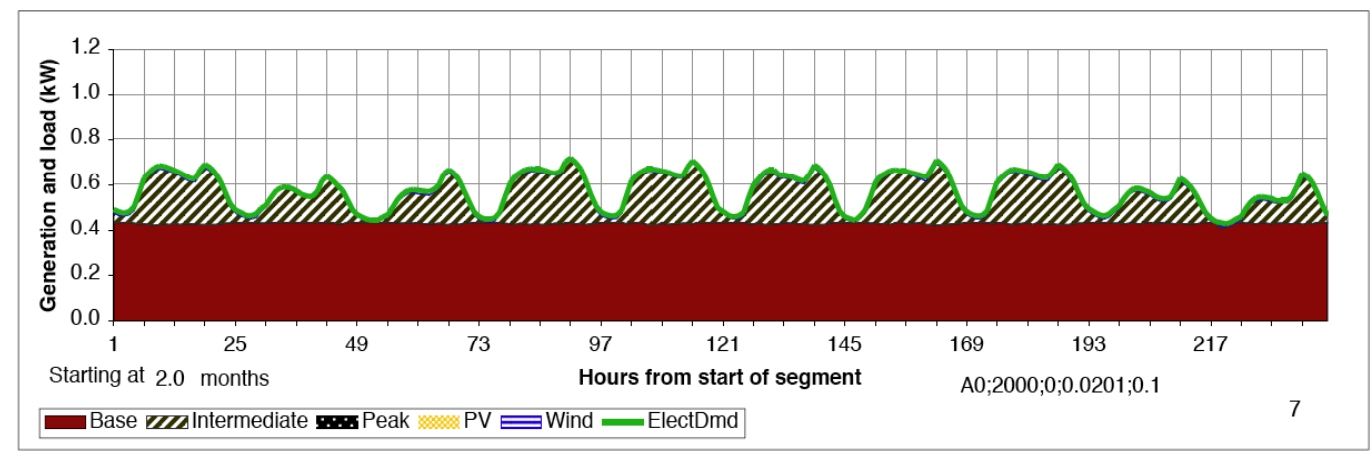

We see the dispatch of wind generation in Figure 11 when there is high wind penetration. In some days the wind generation is substantial and displaces nearly all of the other generation. The base load capacity has declined so that it is only the marginal generator in a few hours (e.g. at around 25 hours, 193 hours, and 220 hours).

Figure 11: Dispatch with high wind penetration in March

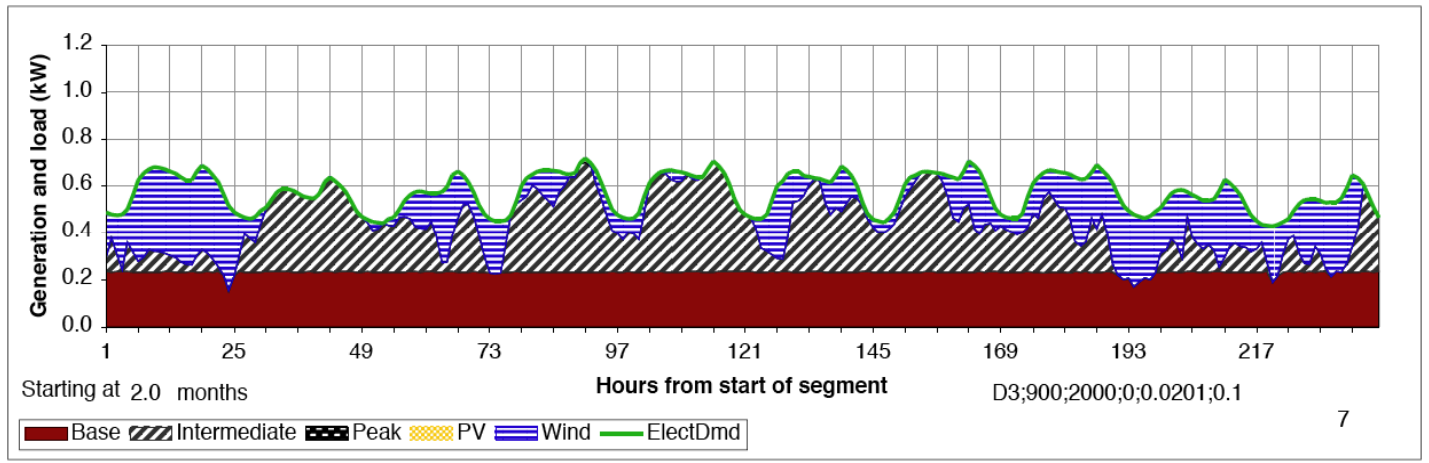


As was mentioned earlier, this wind pattern often generates at night when the demand is low. That means that a relatively small amount of wind capacity will displace all of the intermediate generation in many night-time hours and start to displace the baseload, putting the baseload on the margin. This explains why even a small amount of wind capacity starts to displace the base load. In contrast, the PV generates close to the hours with peak demand. A significant amount of PV capacity can be added to the system before it begins to displace the baseload generation and causes the baseload capacity to decline.

\section{Factors that determine the decline in the marginal value of the intermittent generators}

Figure 8 illustrated the decline in the marginal value of wind generation as it penetrates the system. This section uses the equations developed earlier to illustrate the specific source of this decline in value. We can use equation 10 to examine the components of the value of the wind generators. This is shown graphically in Figure 12. Here the "energy value component" and the "system matching component" are plotted, along with the sum of the two components. The energy value component remains constant up to a penetration of $0.45 \mathrm{kWp}^{2}$ as is predicted above. The system matching component starts out negative and declines steadily as the wind penetrates. This causes the marginal value of the wind to decline with penetration.

Figure 12: Marginal value and marginal cost of wind as function of penetration.

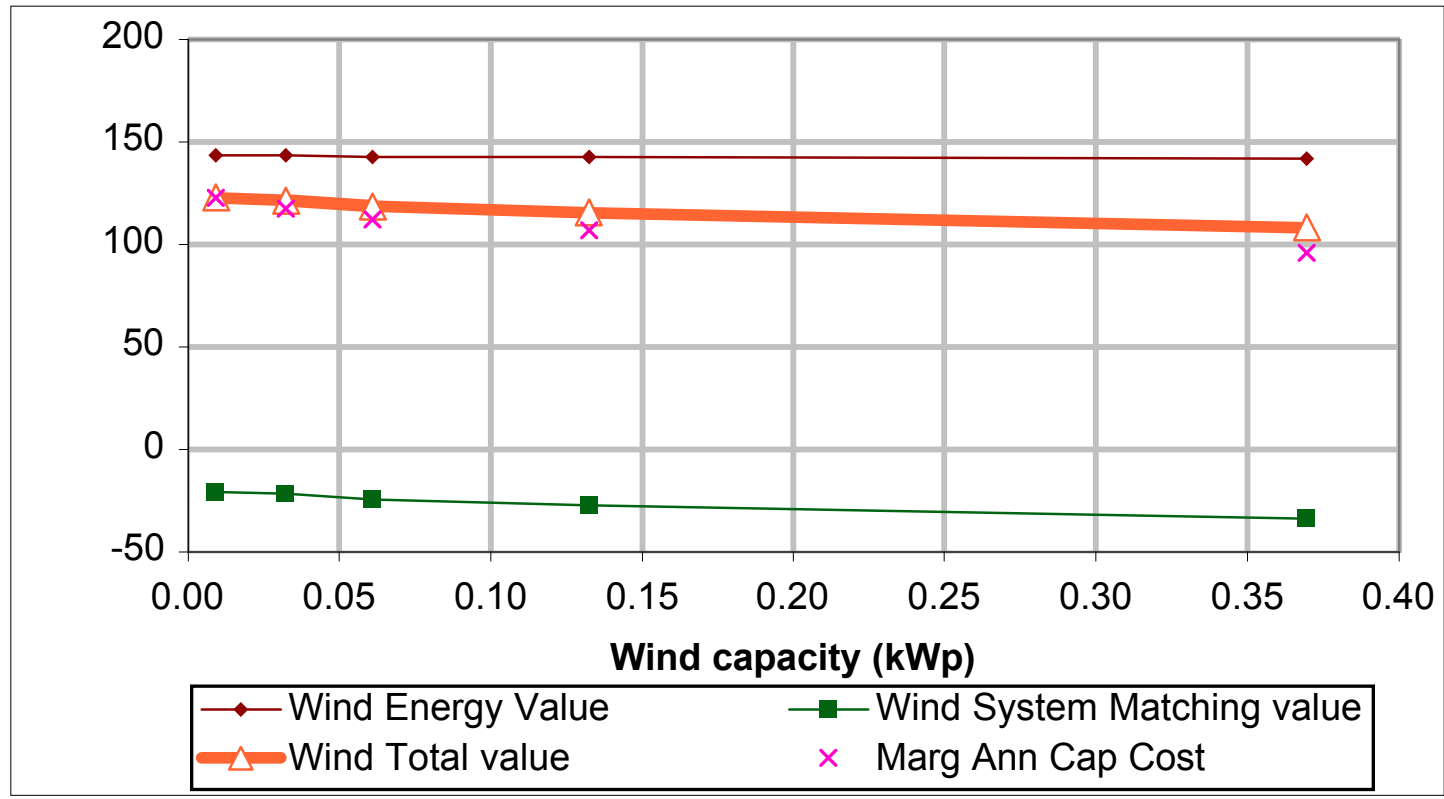

2 Above a penetration of 0.45 , the wind completely displaces the baseload technology in some hours of the year. Therefore the baseload technology is not a baseload generator in the strict sense used here (i.e. it must be at least partially dispatched in every hour of the year). Consequently, Figure 12 is only plotted up to a penetration of 0.45 even though Figure 4 is plotted up to a penetration of 0.65 
Figure 12 also plots the marginal annual costs of the wind generator corresponding to each level of penetration. These coincide with the Total Value curve confirming that in the model solution the marginal cost of the wind generator is equal to the theoretical marginal value of the wind generator.

Figure 13 shows the marginal value and marginal costs for the PV technology as it penetrates the system. Here the system matching component is initially positive due to the fact that the PV tends to generate during the hours with peak system cost. The system matching term does not decline initially because it does not immediately cause the system marginal costs to change.

Figure 13: Marginal value and marginal cost of $P V$ as a function of $P V$ penetration

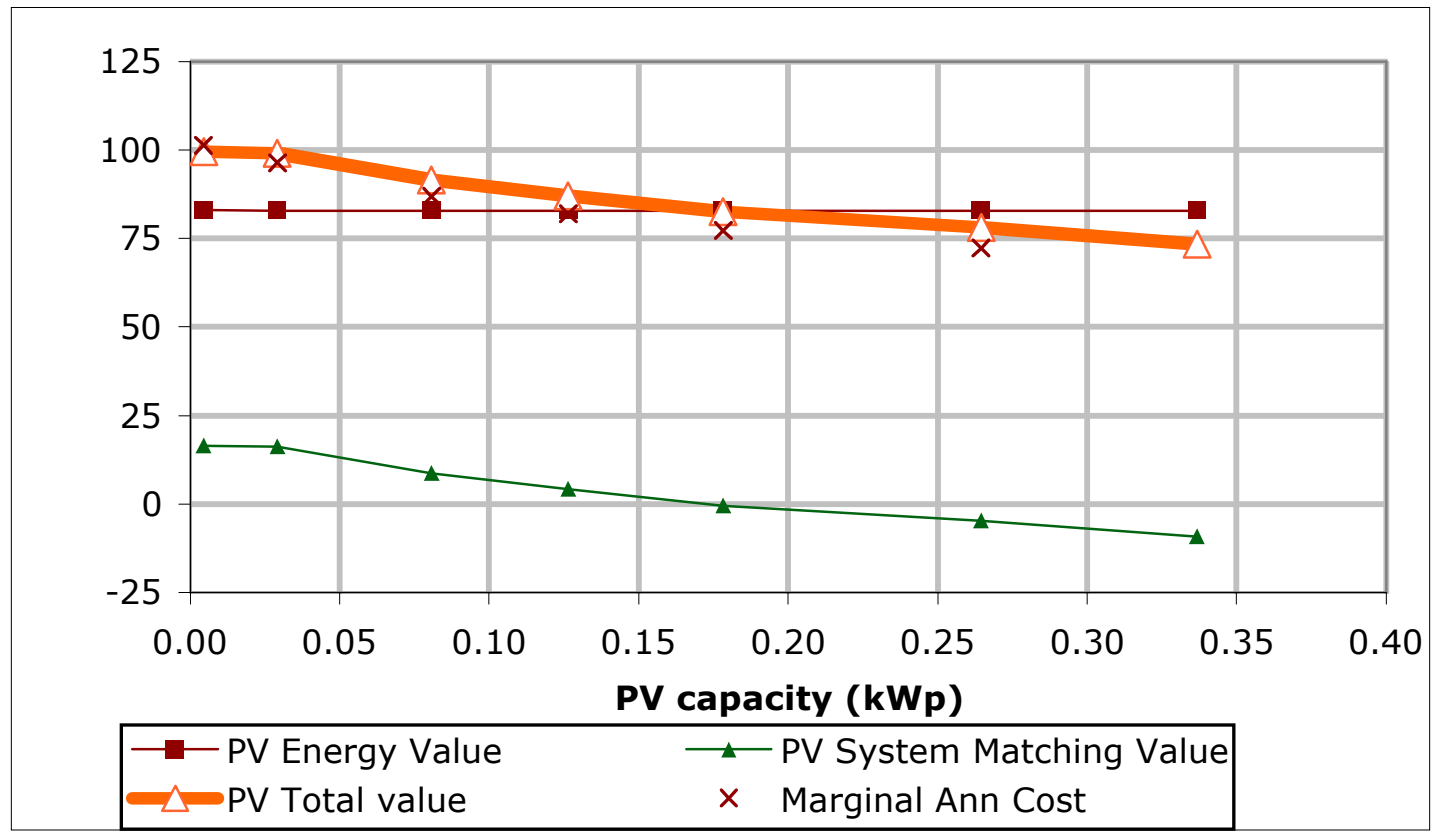

The decline in the system matching term is due to a decline in the covariance between the intermittent's hourly production factors and the hourly system marginal costs. Heuristically, in any hour that an intermittent generator generates close to its capacity, it will displace the more expensive generators on the system, driving down the system marginal cost in those hours. This causes the covariance to become smaller numerically as wind penetrates the system. Figure 14 and Figure 15 illustrate this effect for the wind generator. Figure 14 plots the system marginal cost against the wind production factors for each hour when the wind has not yet penetrated the system. The points fall in three bands corresponding to the marginal cost of the peaker (around 0.05 $\$ / \mathrm{kWh}$ ), the marginal costs of the intermediate generator (at around $0.04 \$ / \mathrm{kWh}$ ), and at the marginal cost of the baseload generator (around $\$ 0.015 / \mathrm{kWh}$ ). This shows a slight negative covariance between the production factors and the marginal system costs. 
Figure 14: System marginal cost vs. wind production factor at 0 wind penetration for the hours of the year (note: vertical scale is truncated to eliminate a few very high cost hours)

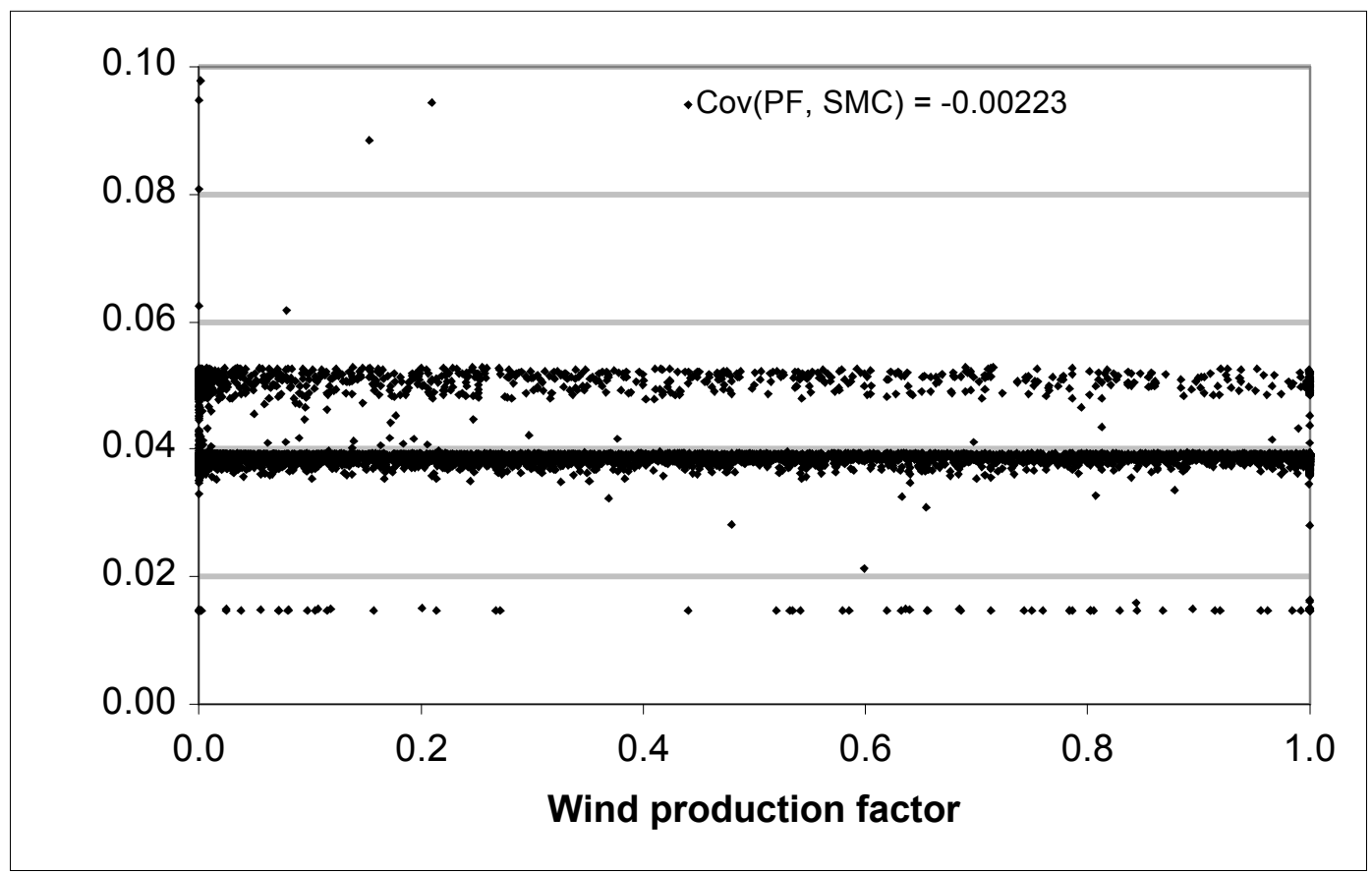

Figure 15 shows the relation between marginal system costs and wind production factors at a high level of wind penetration. The wind production factors are the same as shown in Figure 14. However, the system marginal costs have been driven down in those hours when the wind production factor is high. In those hours the system marginal costs are at or below the marginal cost of the intermediate generator. The result is a more negative covariance between the production factors and the marginal system costs at high wind penetration leading to a smaller marginal value for the wind technology. 
Figure 15: System marginal cost vs production factor at $0.54 \mathrm{kWp}$ wind penetration (note: vertical scale is truncated to eliminate a few very high cost hours)

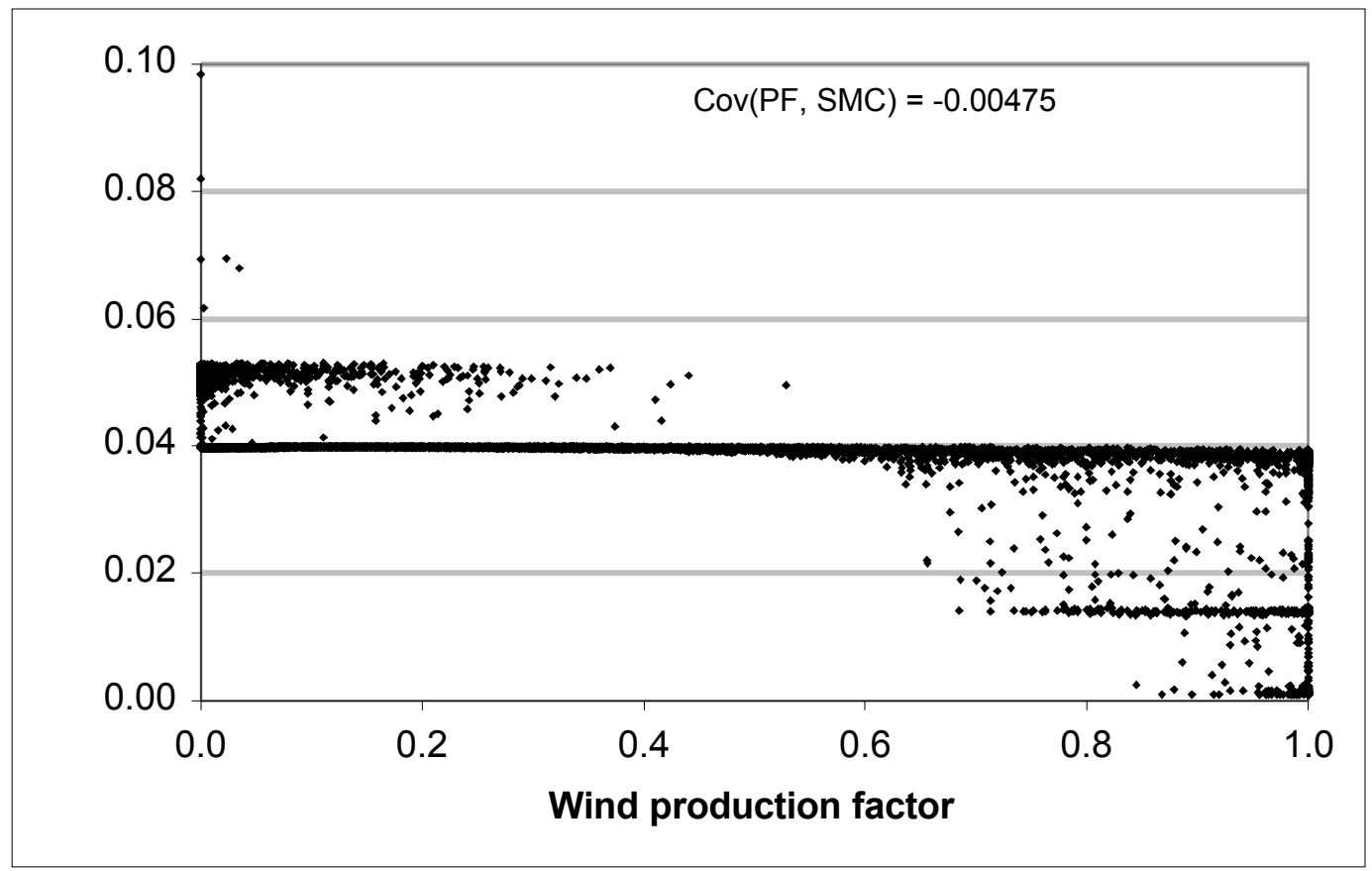

\section{Wind penetration with constrained baseload}

So far the analysis of the penetration has assumed that the balance of the system can adjust optimally as the intermittent technology penetrates. This is representative of the long-term adjustment of the system. In the near-term the capacities of the other generators cannot adjust. This is expected to retard the penetration of the intermittents.

To test the magnitude of the effect several cases were run with the baseload constrained to the capacity that it had with no intermittents in the system. The penetration of wind as a function of its annual costs is shown in Figure 16. Penetration starts at the same annual cost and initially proceeds at the same rate up to the point where there capital cost of wind is about $\$ 112 / \mathrm{yr}$ per $\mathrm{kWp}$ (compare with Figure 2). At this stage in the unconstrained case the baseload capacity began to decrease quickly and the penetration of wind accelerated as a function of its cost. In the constrained case the penetration continues more-or-less linearly since the baseload capacity is not allowed to decrease.

In this example the capacities of the peak and intermediate generators were not constrained. However, they changed very little - the intermediate capacity declines slightly and the peak capacity increases slightly. There is essentially no cost savings in the capacity costs due to the wind penetration. 
Figure 16: Penetration of wind generation when the baseload is constrained to the capacity that is optimal at 0 wind penetration

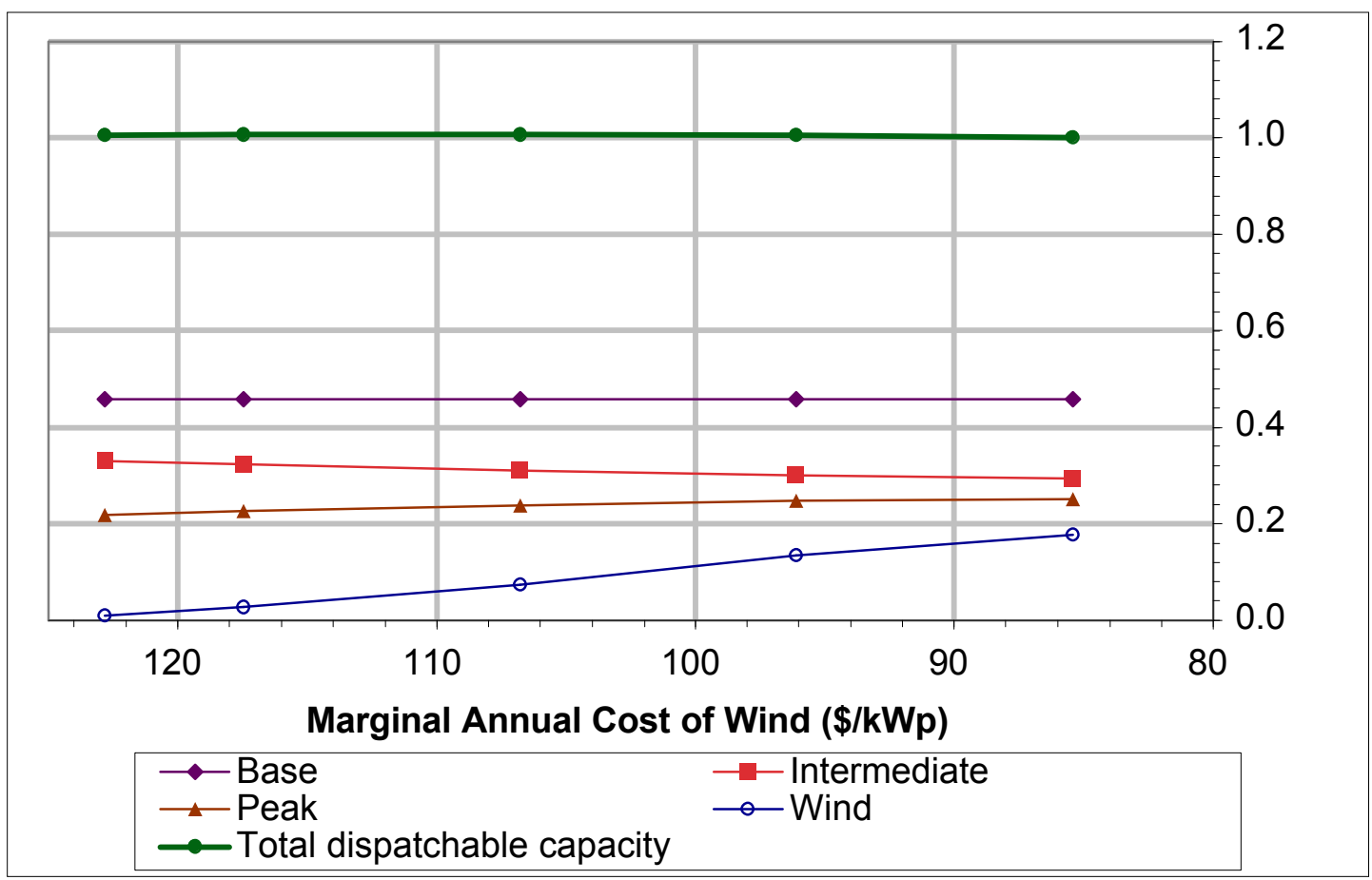

The only significant cost savings resulting from the wind penetration is a reduction in intermediate generation shown in Figure 17. Comparing the unconstrained and the constrained cases illustrates the nature of the intermittent's benefits: in the short run the benefits from intermittent technologies lie in the reduction in operating costs of the rest of the system. While in the long run the saving arises in a change in the composition of capacities and may not include any savings in the operating costs. 
Figure 17: Generation as wind penetrates while baseload capacity is constrained

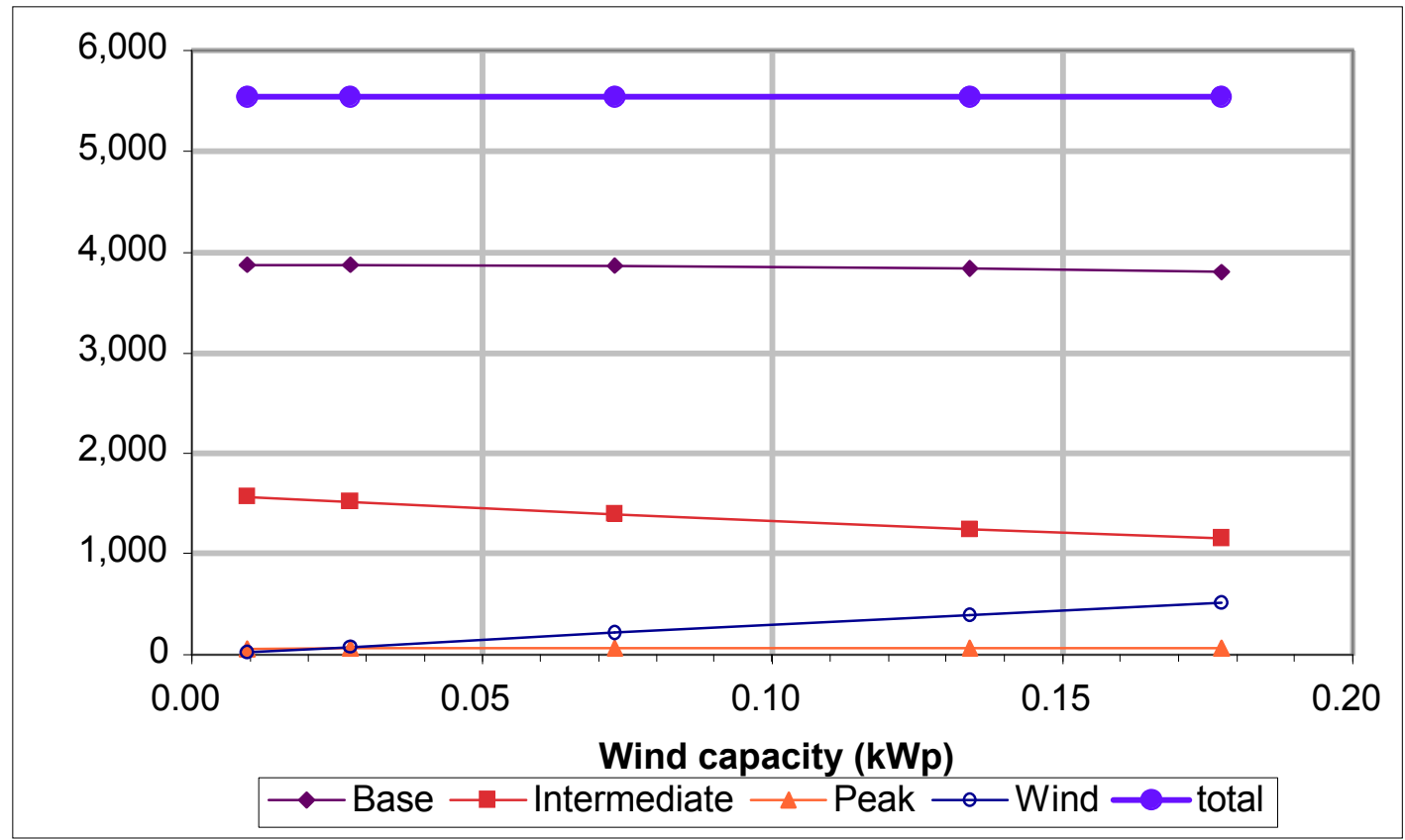

\section{Cross impacts between intermittent technologies}

Since the penetration of an intermittent technology affects the pattern of marginal costs during the year, we would expect that it could affect the marginal value of another intermittent technology. Figure 18 shows such an effect between wind and PV. As the PV penetrates the system, the covariance between the wind generation and the system marginal costs gradually increases, increasing the marginal value of wind. The PV generator tends to reduce the system marginal cost during the mid-day hours - hours when the wind's production factor tends to be small. This increases the covariance between the wind production factor and the system marginal costs corresponding to an increase in the value of the wind generator.

The effects are not necessarily symmetrical: in this model wind penetration had only a slight positive influence on the value of PV. 
Figure 18: Increase in value of the wind as $P V$ penetrates

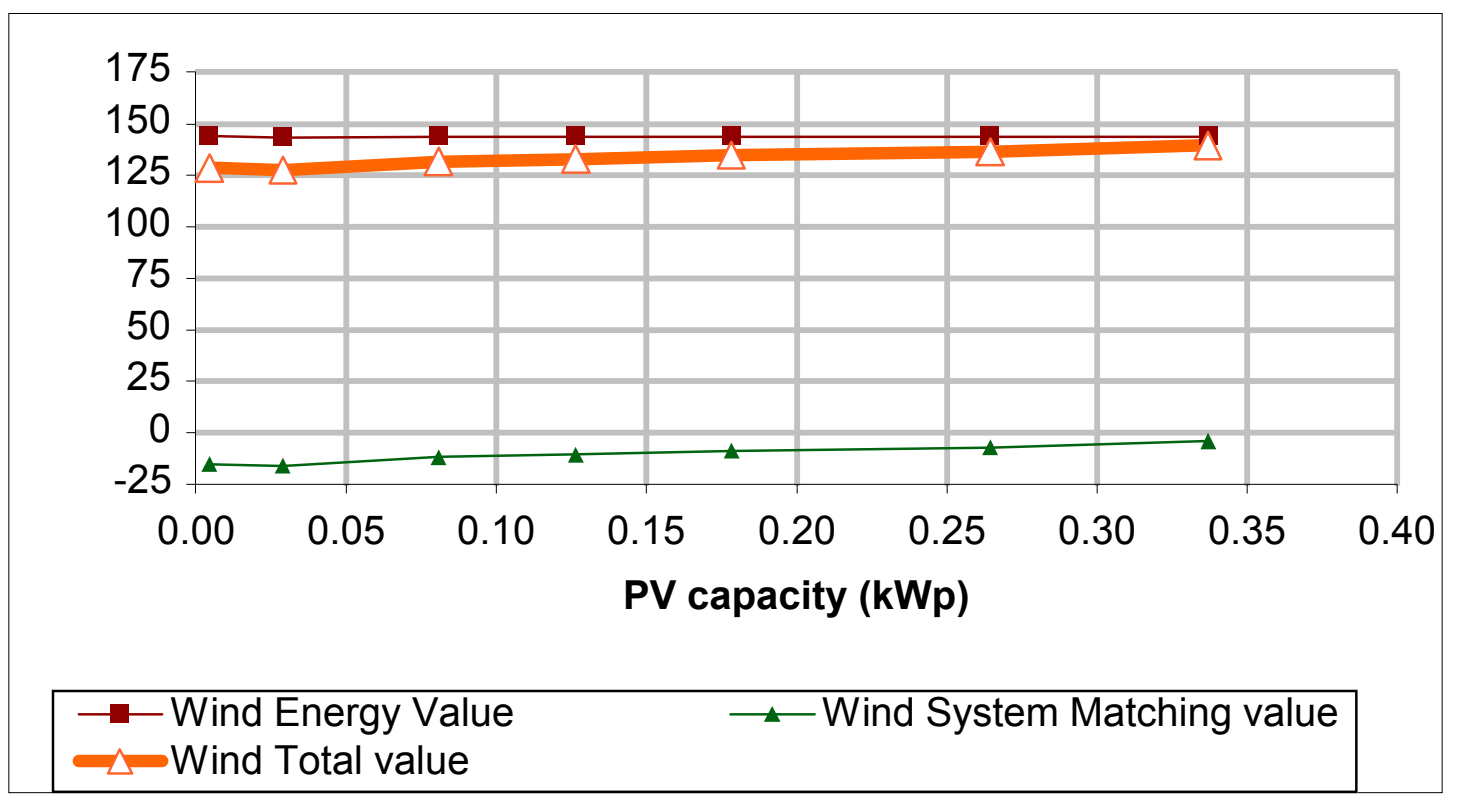

\section{Some practical implications}

\section{Practical implications for the design of intermittent systems}

Several authors have discussed approaches to designing systems with high wind capacity. (e.g. Chowdhury, 1991; Grubb, 1988). It is a frequent assumption that wind sites should be developed so as to smooth out the production from the wind over the year, making the wind appear to be more like a baseload generator. The current analysis, however, focuses on the value of the wind generator in the system. This approach argues that wind should be installed at sites to maximize its value to the system, not to smooth out the production. It should first be installed at the sites with the highest value. As more capacity in added, the marginal value will decline (even if each increment of capacity has the same production pattern). Eventually the value at one site will decline to the point that capacity at another site will have equal value to the system. At that point capacity should be added to the second site.

\section{Implications for carbon management using intermittents}

Possible strategies for carbon management include the use of carbon free technologies such as nuclear, coal with carbon capture and sequestration (CCS), and intermittents. However, these results raise some questions about that approach. In these examples the baseload capacity must be reduced in order to realize high penetration of intermittents. This appears to be inherently due to the fact that intermittent generation tends to have a high variance-full power in some hours and none in others. When generating at full power the intermittent displaces the baseload generation, and eventually leads to a reduction in optimal baseload capacity. The baseload generation is replaced by a combination of intermittent and intermediate generation. Since intermediate generation is typically natural gas fired, the system tends to trade carbon free nuclear or CCS coal 
baseload generation for natural gas generation. Carbon management policies would need to be designed to cope with this tendency.

\section{Conclusions}

This study has examined the value of intermittent technologies from the standpoints of theoretical optimization and systems modeling. From the theory, we can derive a basic expression for the marginal value of intermittent capacity, taking into account the conditions on the system. The long-term value of an intermittent can be divided into two components. One is a function of the capacity factor of the intermittent. This component of value stays constant as the intermittent penetrates the system (up to the point that there is enough intermittent capacity to make it the marginal generator some hours of the year). The other component is a function of the covariance between the intermittent generation and the system marginal costs. This component does decline as the intermittent penetrates the system since the intermittent displaces higher cost generators in each hour that it generates, reducing the system marginal costs in those hours. From a practical point of view, this expression can predict the cost at which the technology will begin to penetrate the system.

From a broader perspective, the theory tells us that the conditions governing the economic penetration of intermittents change as intermittent capacity grows. This suggests that there is an opportunity to design systems of high intermittent capacity so that each increment of capacity is optimal.

Consonant with other authors, this study finds the largest component of value from intermittents comes from the long-term reduction baseload capacity. Such a shift is needed if we are to expect high penetration of intermittents. At the same time, this will make it difficult to implement strategies of carbon management that count on intermittents coupled with either nuclear baseload or carbon sequestered coal baseload technologies. This is not to say that it is an insoluble problem, just that additional work should be done to examine how we can best design low carbon systems in the long-term.

\section{Acknowledgments}

The author would like to thank Tom Edmunds for his review of this paper and Alex Farrell for his review and comments on an earlier draft. 


\section{Appendix A: Parameters and data for model}

Demands: data for California 2001 (CAISO), normalized to a maximum of 1.0

Wind: data from Tehachapis for 2001 (Jackson)

PV data for Sacramento 2001 (pointed south, tilted at latitude) (NREL)

Natural gas price: $\$ 6 / \mathrm{mmBtu}$

Nuclear fuel cost 4.6 mills/kWh

Interest rate $10 \%$

For wind and PV capital costs varying values are used as shown in the figures. The capital and operating costs of other technologies are given in Table 2

Table 2: Cost parameters of technologies

\begin{tabular}{|c|c|c|c|c|c|c|c|}
\hline Technology & $\begin{array}{l}\text { Total Over- } \\
\text { night Costs } \\
(2001 \$ / k w)\end{array}$ & $\begin{array}{l}\text { Fixed } \\
\text { O\&M } \\
(2001 \\
\$ / \mathbf{k w})\end{array}$ & $\begin{array}{l}\text { Life } \\
\text { (yrs) }\end{array}$ & \begin{tabular}{|l|} 
Present \\
Value \\
Fixed \\
O\&M \\
cost \\
$(2001 \$$ \\
$/$ kw) ${ }^{1}$
\end{tabular} & $\begin{array}{l}\text { Total } \\
\text { Capital } \\
\text { cost } \\
(2000 \$ \\
/ \mathbf{k w})^{2}\end{array}$ & $\begin{array}{l}\text { Variable } \\
\text { O\&M } \\
(2001 \$ \\
\text { mill/kwh) }\end{array}$ & $\begin{array}{l}\text { Heat } \\
\text { Rate } \\
\text { (Btu } \\
\text { /kwh) }\end{array}$ \\
\hline $\begin{array}{l}\text { Peak: } \\
\text { Advanced } \\
\text { Combustion } \\
\text { Turbine }\end{array}$ & 460 & 8.17 & 20 & 69.55 & 529.55 & 3.07 & 8550 \\
\hline $\begin{array}{l}\text { Intermediate: } \\
\text { Advanced } \\
\text { Gas/Oil } \\
\text { Combined } \\
\text { Cycle }\end{array}$ & 608 & 10.22 & 30 & 96.34 & 704.34 & 2.04 & 6350 \\
\hline $\begin{array}{l}\text { Base: } \\
\text { Advanced } \\
\text { Nuclear }\end{array}$ & 2117 & 58.48 & 30 & 551.28 & $\begin{array}{l}2668.2 \\
8\end{array}$ & 0.43 & 10400 \\
\hline
\end{tabular}




\section{Appendix B: Model solution procedure in META•Net}

META $\cdot$ Net solves these equations by exchanging price and quantity information between nodes each hour until the conditions in equations 5 and 6 are satisfied. The algorithm is illustrated in Figure B1. The demand nodes send down a quantity demanded. The market nodes allocate total demand among the generators based on prices provided by the generators (generators with lower prices receive higher allocations).

When a generator's allocation is less than its capacity, it sends a price equal to its operating cost. Such a low cost can elicit a demand that exceeds the capacity of the generator. In that case, over a series of iterations the generator increases its price. As the price increases, the market allocates less demand to the generator until a price is found such that demand sent to the generator is equal to its capacity. If the market nodes are highly price sensitive, this price is approximately equal to the system marginal cost, $\lambda_{h}$. Based on this, the generator can make an accurate estimate of $\lambda_{h}$ and estimate $\gamma_{g, h}$. Through a series of iterations, it can adjust its capacity until the condition in equation 6 is met.

This can be interpreted as a market in which each supplier to the market (i.e. each generator) receives as payment the marginal cost in the market. It then can make the financial calculation as to whether or not additional increments of capacity would earn an acceptable rate of return and increase or decrease its capacity accordingly. 
Figure B1: Schematic of META-Net model

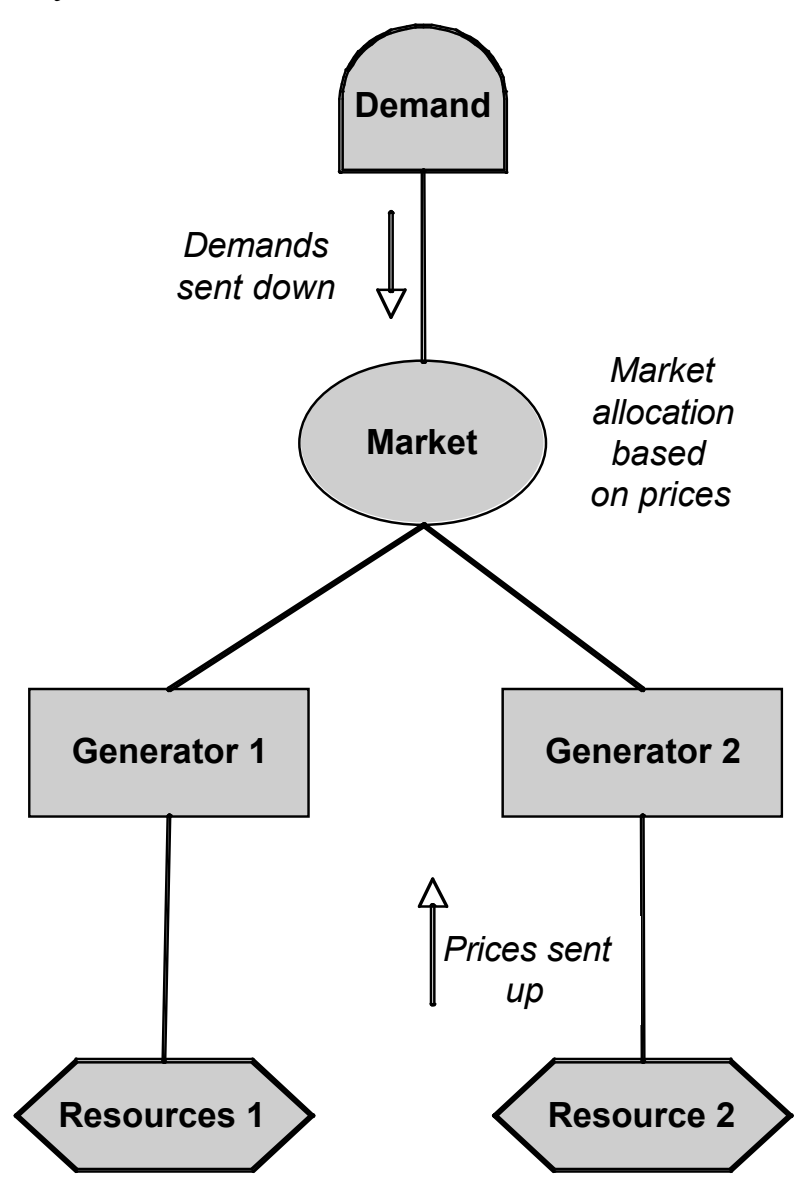

\section{References}

Bouzguenda M, and Rahman S. Value analysis of intermittent generation sources from the systems operations perspective. IEEE Transactions on Energy Conversion. 1993; v8 n3; 484 - 490

DeCarolis JF, and Keith DW. The costs of wind's variability: is there a threshold?. The Electricity Journal. 2005; January-February; 69 - 77

California Independent Systems Operator (CAISO). OASIS data base.

http://oasis.caiso.com/

Chowdhury BH. Assessment of the economic value of wind generated power of electric utilities. Electric power systems research 1991; 21; 33 - 42

Energy Information Administration (EIA), The electricity market module of the national energy modeling system: Model documentation report, DOE/EIA-M068(2001). 2001

Energy Information Administration (EIA) 2003a, Assumptions for the Annual Energy Outlook 2003, DOE/EIA-0554(2003). 2003; Table 40 
Grubb, MJ. The potential for wind energy in Britain. Energy Policy. 1988; December; $594-607$

Grubb, MJ. The integration of renewable electricity sources. Energy Policy 1991;

September; 670 - 688

Hogan WW, and Weyant JP. "Combined Energy Models", in Advances in the Economics of Energy and Resources, Vol. 4. JAI Press Inc. 1982, p 117-150

Jackson K. Wind power generation trends. CWEC-2003-01. California Wind Energy Collaborative. 2003

Kelly H, Weinberg CJ. Utility strategies for using renewables. In: Johansson TB, Kelly H, Reddy AKN, Williams RH. Renewable energy: sources for fuels and electricity. Island Press: Washington; 1993

Kirby, B., Milligan M, Makarov Y, Hawkins D, Jackson K, and Shiu H. California RPS integration cost analysis-phase I: one year analysis of existing resources, Report No. 500-03-108C. 2003

Hirst E, and Hild J. The value of wind as a function of wind capacity. The Electricity Journal 2004; July; 11 - 20

National Renewable Energy Laboratory (NREL). PVWatts http://medc.nrel.gov/splar/codes_algs/PVWATTS/version1/California/

Shaalan HE. Generation of electric power. In Beaty HW (ed.) Handbook of electric power calculation, $3^{\text {rd }}$ ed. McGraw-Hill; 2003

Short W, Blair N, Heimiller D, and Singh V. Modeling the long-term market penetration of wind in the United States, NREL/CP-620-34469, National Renewable Energy Laboratory; 2003

Stoft S. Power systems economics. Wiley-Interscience; 2002 